Check for updates

Cite this: J. Mater. Chem. B, 2020 8,6233

Received 29th January 2020

Accepted 26th February 2020

DOI: $10.1039 / \mathrm{d} 0 \mathrm{tb} 00260 \mathrm{~g}$

rsc.li/materials-b

\section{Smart diagnostic nano-agents for cerebral ischemia}

\author{
Christos Tapeinos, ${ }^{*^{a}}$ Matteo Battaglini, $\dagger^{\mathrm{ab}}$ Attilio Marino $\dagger^{\mathrm{a}}$ and Gianni Ciofani (D) $\star^{a}$ \\ Cerebral ischemia (or ischemic stroke) is undeniably one of the most important life-threatening cerebral \\ disorders. It occurs due to a clot formation in one of the blood arteries supplying the brain, causing a \\ reduction or interruption of the blood flow. To date, the use of thrombolytics like the recombinant \\ tissue plasminogen activator or the use of mechanical thrombectomy are the only two food and drug \\ administration-approved treatments. However, these cannot be applied without first evaluating the \\ beneficial or adverse effects on the patient. Thus, imaging is decisive for identifying the appropriateness \\ of each stroke patient, leading potentially to improved therapeutic outcomes. In this review, we will \\ present a variety of diagnostic nano-agents, and a few theranostic ones, for the assessment of ischemic \\ stroke, highlighting their strengths and weaknesses.
}

\section{Introduction}

Neurological disorders derived from cerebrovascular abnormalities like ischemic stroke are the third leading cause of morbidity and the second leading cause of mortality worldwide. ${ }^{1}$ Cerebral ischemia occurs due to an artery occlusion (thrombosis) and the inhibition of blood flow to the brain that subsequently leads to neuronal cell death. Neuronal death is followed by impairment of certain functions of the brain and brings cognitive, speech, and motor problems. The severity of these problems depends on the extent of the infarcted area (ischemic area), and on the time between ischemia and the restoration of the blood flow. Stroke can be divided into ischemic stroke, transient ischemic attack, and hemorrhagic stroke. ${ }^{2}$ Ischemic stroke can be thrombotic or embolic. In the former case, a blood clot is formed either in large blood-supplying arteries such as the carotid or the middle cerebral or in smaller, deeper penetrating arteries. In the latter case, a blood clot (embolus) is created somewhere else rather than the brain (e.g., in the heart) and travels in the bloodstream until it forms a clot that will eventually affect the brain. The formation of small clots that temporarily inhibit the blood flow into the brain is called transient ischemic attack (TIA), and although it is not so severe as the ischemic and the hemorrhagic stroke, it inevitably increases the potential of a subsequent one. In contrast to ischemic stroke and TIA, hemorrhagic stroke is created due to the burst of a blood

\footnotetext{
${ }^{a}$ Istituto Italiano di Tecnologia, Smart Bio-Interfaces, Viale Rinaldo Piaggio 34, 56025 Pontedera, Pisa, Italy.E-mail:christos.tapeinos@iit.it, gianni.ciofani@iit.it

${ }^{b}$ Scuola Superiore Sant'Anna, The Biorobotics Institute, Viale Rinaldo Piaggio 34, 56025 Pontedera, Pisa, Italy

$\dagger$ These Authors equally contributed to this work.
}

vessel, resulting in blood leakage inside the brain. A more detailed description of the types of stroke as well as the pathophysiology and the therapeutic approaches for this disease have been already described elsewhere, ${ }^{3,4}$ and will not be presented here.

To date, the food and drug administration (FDA)-approved treatments for ischemic stroke comprise the use of tissue plasminogen activator (tPA), a thrombolytic substance, as well as the use of mechanical thrombectomy. ${ }^{5,6}$ Although these methods can restore the blood flow and reduce the cellular death in the "penumbra" (the zone surrounding the ischemic core), they are limited firstly by side effects like cerebral hemorrhage, and secondly, by the fact that not all patients can undergo one of these treatments: the majority of patients arrive at the hospital after the therapeutic window of 3 hours, being thus unsuitable for tPA administration. Furthermore, the lack of proper imaging of the ischemic area and the subsequent identification of patients that will be favored from these procedures also represent a significant obstacle in the immediate stroke treatment. Other reasons include age, big clots that cannot be removed by using tPA only, history of a previous stroke, and many more, which are described in detail elsewhere. ${ }^{7,8}$

In addition, restoration of the blood flow (reperfusion) increases the production of the reactive oxygen and nitrogen species (ROS and RNS, respectively) and the secretion of pro-inflammatory molecules, causing further damage to the ischemic area. ${ }^{9}$

New nano-therapeutics combined with novel nano-imaging agents have been developed to overcome these limitations. ${ }^{4}$ In spite of the fact that these novel tools hold great potential in replacing the current techniques, still the post-diagnosis and post-ischemic stroke complications, in combination with other anatomical (e.g., physical, chemical and biological) barriers like 
the blood-brain barrier (BBB), hinder an efficient treatment and the complete recovery of stroke patients.

A variety of imaging methods has been developed, aiming at improving the therapeutic effect of the current and future treatments. ${ }^{10}$ The main goal of these methods is to assess the extent of the damage due to ischemia, and subsequently identify which patients are eligible to undergo conventional and non-conventional (nano-therapeutics) treatments. The developed imaging methods that are currently used are computed tomography (CT), single-photon emission computed tomography (SPECT), intravital microscopy (IVM), magnetic resonance imaging (MRI), positron emission tomography (PET), and very recently magnetic particle imaging (MPI). Nowadays, these imaging techniques have significantly improved and are used not only for stroke diagnosis but also to evaluate the efficiency of the administered therapies, as well as to predict the risk of another stroke. Although some of them (IVM, CT/SPECT) can image the infarcted tissue without any external contrast agent, the majority of them make use of chemical substances (PET) and/or nanoparticles (MRI, MPI) that further enhance the imaging modality.

Each of the developed imaging contrast agents is carefully designed aiming for the highest efficiency at the lowest possible concentration, and to realize this, proper functionalization that imparts tailor-made characteristics is applied. This functionalization smartly improves the agent's blood circulation time, their ability to cross the $\mathrm{BBB}$, and their contrast capability, making them appropriate for a valuable evaluation of the ischemic damage and of the effect of each nano-therapeutic (if and whenever applied). Taking into consideration the aforementioned, in this review, we aim to update the scientific community on the advances ( $<5$ years) in smart diagnostic nano-agents for cerebral ischemia, and to briefly describe the advantages and disadvantages of the above-mentioned imaging techniques, either alone or in combination (multi-modal imaging). Several examples of smart nano-agents that act both as imaging and as therapeutic agents are also discussed.

\section{Computed tomography (CT)}

Non-contrast computed tomography (CT) has been considered for a long time the gold standard for the initial evaluation of patient conditions in acute ischemic stroke. ${ }^{11} \mathrm{CT}$ is a noninvasive imaging technique based on the attenuation of X-ray by tissue and organs, in which the different attenuation caused by the thickness and the density of different tissues of X-rays is reconstructed in a grayscale image. ${ }^{12}$ By rotating the X-ray source around the under examination object, it is possible to obtain a $3 \mathrm{D}$ reconstruction based on the X-ray attenuation. ${ }^{13}$ Various organs and tissues can be imaged thanks to their properties without the use of any contrast agents (CAs).

However, in many cases, for the imaging of soft tissues and biological structures in contact with body fluids, the use of CAs is necessary. ${ }^{13}$ The most used class of CAs for CT are the iodinated compounds. Due to the high atomic number of
Iodine $(Z=53)$, these compounds grant better attenuation of $\mathrm{X}$-ray when compared to biological tissues. ${ }^{13}$ Usually, noncontrast-based CT is used for early assessment of ischemic stroke by monitoring parameters like insular ribbon sign, obscuration of the lentiform nucleus, and hyperdense artery sign. ${ }^{14}$ Additionally, non-contrast CT analysis is associated with Alberta Stroke Program Early CT Score (ASPECTS), a semiquantitative pre-treatment score used to assess how many vascular territories of the middle cerebral artery (MCA) are affected by stroke, in order to provide fast information about the outcome of a thrombolysis treatment of the patient and predict the presence of hemorrhage. ${ }^{15}$ Despite the usefulness of this assessment, non-contrast CT has very low sensitivity in the hyper-acute stage of ischemic stroke (usually considered in the first three hours of the onset), generating several problems for the optimization of the therapy. ${ }^{14}$

When comparing the various non-contrast-based CT with other diagnosis techniques like MRI, commonly used CT set-ups are able to provide diagnostic information in less than a minute, although they are far less precise than MRI. ${ }^{16}$ In particular, noncontrast-based CT usually presents reduced sensitivity to the infarct zone of brain parenchyma. ${ }^{15}$ This considered, non-contrast-based CT is commonly associated with CA-based techniques used to provide more useful and precise information, like CT-angiography (CTA) and CT-perfusion (CTP), in the so-called multi-modal CT. ${ }^{14}$ In CTA, the injection of an iodinated CA is used to map the brain vasculature. On the other hand, СТP involves the sequential acquisition of CT images during the administration of an iodinated CA, granting useful information about the brain blood flow and volume, and an estimation of the infarcted cerebral tissue or of the risk of an infarction. ${ }^{16,17}$ When imaging brain vasculature and tissue perfusion, CTP and CTA are also faster than MRI but fall short in terms of the high radiation required for the imaging, and because of the potential high renal toxicity. ${ }^{15,17}$

CAs based on iodinated small molecules commonly used in CT have significant drawbacks including (a) high required doses of use due to low X-ray attenuation properties, (b) high viscosity and osmolarity that can lead to various forms of toxicity, and (c) small size that causes their rapid clearance from the body. ${ }^{13}$ CAs for CT/SPECT are even more complicated because there is the need to use radioisotope-based CAs for SPECT and high X-ray attenuation molecules for CT. This combination leads to an enhanced toxicological effect leading to undesired interaction between the two classes of CAs that can cause artifacts in imaging. ${ }^{18}$ Therefore, the development of innovative CAs with high biocompatibility, good tissue retention, and optimal imaging properties is of pivotal importance. A summary of several works on smart CT nano-agents is presented in Table 1.

Glycol-chitosan-coated gold nanoparticles (GC-AuNPs) are one of the nano-agents that has been used as a CA in CT imaging. In particular, fibrinogen functionalized GC-AuNPs demonstrated the ability to specifically target cerebral thrombus acting as a diagnostic agent for ischemia (Fig. 1). ${ }^{19}$

Approaches involving liposomal-based CAs in CT-based imaging have been investigated for a long time, usually involving 
Table 1 Recent works exploiting smart diagnostic nano-agents for CT imaging in cerebral ischemia

\begin{tabular}{|c|c|c|c|c|c|c|c|c|}
\hline Material & Functionalization & Size & $\begin{array}{l}\text { Amount/ } \\
\text { concentration }\end{array}$ & $\begin{array}{l}\text { Synthetic } \\
\text { procedure }\end{array}$ & In vivo model & Technique & Target of the study & Ref. \\
\hline fib-GC-AuNPs & $\begin{array}{l}\text { Glycol-chitosan } \\
\text { and fibrin-targeting } \\
\text { peptide }\end{array}$ & $30 \mathrm{~nm}$ & 2 and $20 \mathrm{mg} \mathrm{kg}^{-1}$ & $\begin{array}{l}\text { Stirring under } \\
\text { heating }\end{array}$ & $\begin{array}{l}\text { Male C57Bl/6 mice } \\
\text { (thromboembolic) }\end{array}$ & CT & $\begin{array}{l}\text { Direct cerebral } \\
\text { thrombus imaging } \\
\text { through CT }\end{array}$ & 19 \\
\hline $\begin{array}{l}\text { Liposomal- } \\
\text { iodinated CA }\end{array}$ & N/A & $140 \mathrm{~nm}$ & $\begin{array}{l}1.1 \text { and } 2.2 \mathrm{~g} \text { iodine } \\
\text { per } \mathrm{kg}\end{array}$ & $\begin{array}{l}\text { Water-solvent } \\
\text { extrusion }\end{array}$ & $\begin{array}{l}\text { Male C57BL6/J } \\
\text { mice }\end{array}$ & CTA & $\begin{array}{l}\text { Imaging of large cere- } \\
\text { brovascular networks }\end{array}$ & 22 \\
\hline $\begin{array}{l}\text { Iodinated } \\
\text { dendritic }\end{array}$ & N/A & $\begin{array}{l}13,16, \\
19 \text { and } \\
22 \mathrm{~nm}\end{array}$ & $\begin{array}{l}300 \mu \mathrm{L} \text { for PAMAM, } \\
200 \mu \mathrm{L} \text { for Fenestra } \\
\mathrm{VC} \text {, and } 50 \mu \mathrm{L} \text { for } \\
\text { Iohexol for each } 20 \mathrm{~g} \\
\text { mouse }\end{array}$ & $\begin{array}{l}\text { Mixture under } \\
\text { stirring }\end{array}$ & Male C57BL/6 mice & CT & $\begin{array}{l}\text { Tumor imaging } \\
\text { through CT }\end{array}$ & 23 \\
\hline $\begin{array}{l}{ }^{99 m_{T}} \text { Tc-HMPAO, } \\
\text { 99m Tc-DTPA and } \\
{ }_{\text {99m }} \text { Tc-annexin } \\
\text { V-128 }\end{array}$ & $\mathrm{N} / \mathrm{A}$ & N/A & $\begin{array}{l}20-37 \mathrm{MBq} \text { per } \\
\text { animal }\end{array}$ & $\begin{array}{l}\text { N/A } \\
\text { (commercial) }\end{array}$ & $\begin{array}{l}\text { Male Sprague- } \\
\text { Dawley rats (MCAO) }\end{array}$ & CT-SPECT & $\begin{array}{l}\text { Imaging of blood- } \\
\text { flow, BBB disruption, } \\
\text { and apoptosis after } \\
\text { cerebral ischemia }\end{array}$ & 24 \\
\hline $\begin{array}{l}\text { PAA modified } \\
\beta-\mathrm{NaGdF}_{4}: \mathrm{X}^{\circ} \\
\mathrm{Eu}^{3+} \\
\text { nanoparticles }\end{array}$ & N/A & $9 \mathrm{~nm}$ & $0.75 \mathrm{mg}$ per animal & Coprecipitation & $\begin{array}{l}\text { Female nude } \\
\text { mouse model }\end{array}$ & XLCT & $\begin{array}{l}\text { In vivo imaging of } \\
\text { nude mice }\end{array}$ & 25 \\
\hline
\end{tabular}
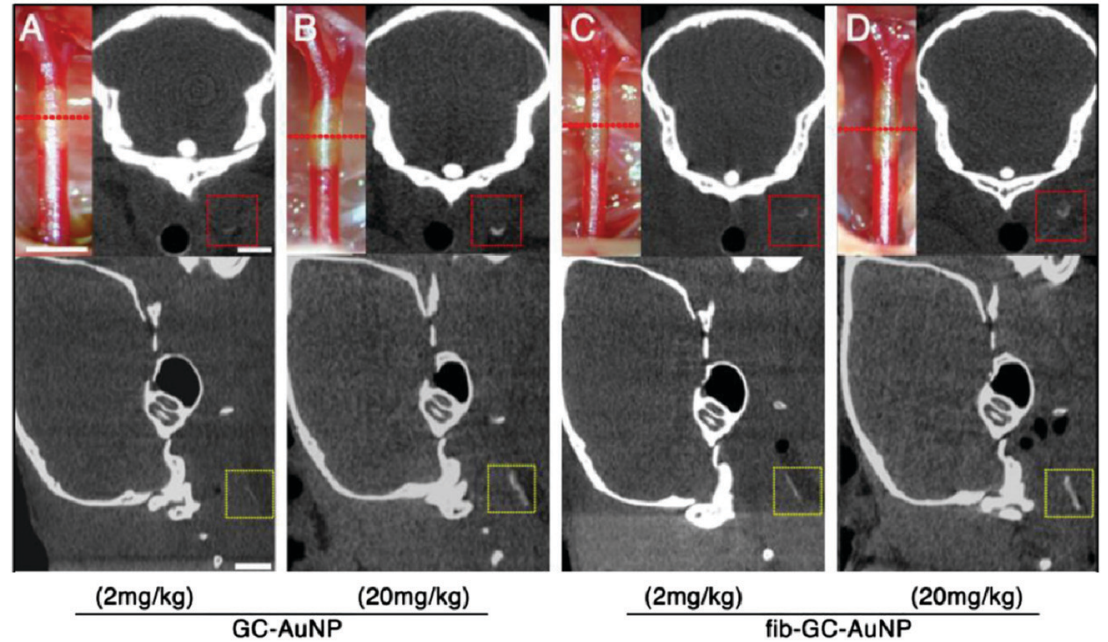

Fig. 1 Targeted fib-GC-AuNPs are superior to non-targeted GC-AuNPs in mCT imaging of in situ carotid thrombus. (A-D) Representative mCT images of in situ carotid thrombosis. Thrombi were formed in C57BI/ 6 mice by applying stripes of filter paper $\left(1 \times 1 \mathrm{~mm}^{2}\right)$ soaked in $10 \%$ FeCl to the left distal carotid artery (photographs, upper row). Thirty minutes later, $\mathrm{mCT}$ thrombus images (upper row, coronal view; lower row, sagittal view) were acquired 5 minutes after intravenous injection of $200 \mu \mathrm{L} \mathrm{GC}$-AuNPs ( $\mathrm{A}$ and B) or fib-GC-AuNPs (C and D) of either a low (2 mg kg ${ }^{-1} ; A$ and C) or high (20 mg kg ${ }^{-1}$ ); (B and D) concentration. At the low administered doses, fib-GC-AuNPs (D) outperforms GC-AuNPs (C), by more clearly marking the carotid thrombus. The "larger" thrombus in (C) vs. (A) reflects better clot visualization due to more avid binding of the targeted compound. At high administered doses, the areas of thrombus-related hyperdense lesions look similar between the animals injected with either GC-AuNPs (B) or fib-GC-AuNPs (D). Adapted with permission from Kim et al. ${ }^{19}$ Copyright 2015 Ivyspring.

the loading of iodinated water-soluble molecules in the inner core of liposomes. ${ }^{20,21}$ In one of these approaches, liposomes of an average size of $140 \mathrm{~nm}$ were used as CA for imaging and mapping the extensive brain vasculature, including the circle of Willis, being able to image even vessels as small as $40 \mu \mathrm{m}$. Moreover, these liposomal-based CAs were also used to image the brain of actin alpha-2 (ACTA2) mutant mice, being able to show the morphological alteration in the brain vasculature caused by this mutation. ${ }^{22}$ Even if not strictly-related to ischemic stroke, the example of four amine-terminated polyamidoamine (PAMAM) dendrimers as CAs for CT imaging of tumor in in vivo animal models is really interesting, and the application of these nanostructures in ischemic stroke CT-based imaging could provide insightful information. These dendrimer-based CAs demonstrated the ability to accumulate in tumors thanks to the enhanced permeation and retention (EPR) effect, causing a contrast enhancement in the affected areas. More interestingly, these nanostructures showed little to no toxic effect and a complete clearance from the liver and the spleen between 30 and $60 \mathrm{~d}$ post-injection (p.i.). ${ }^{23}$

Polyethylene glycol (PEG)-functionalized gold (Au) nanoparticles with star shape (AuNS@PEG) have also been proposed as CAs for in vivo CT enhanced imaging. AuNS showed good $\mathrm{X}$-ray attenuation properties, probably due to their increased surface area when compared to spherical Au nanoparticles. Moreover, AuNS@PEG showed good CAs capabilities in vivo, 
together with high biocompatibility, stability, and excellent renal clearance properties. ${ }^{12}$ As previously mentioned, CT/ SPECT is still somewhat limited when compared to CT. However, some interesting works have proven the potential of this technique in the study of brain stroke. As an example, the possibility to image and analyze in vivo the alterations of brain blood flow, the disruption of BBB, and the apoptosis caused by focal cerebral ischemia have been reported. ${ }^{24}$ In this study, the chosen agents included the commercially available technetium $\left({ }^{99 \mathrm{~m}} \mathrm{Tc}\right)$ exametazime (HMPAO), the ${ }^{99 \mathrm{~m}} \mathrm{Tc}$ diethylenetriaminepentaacetic acid (DTPA), and the experimental ${ }^{99 \mathrm{~m}} \mathrm{Tc}$-annexin $\mathrm{V}$-128. As the authors commented in their work, the analysis of these biological parameters could become an appealing tool in the clinical evaluation of stroke.

Lastly, an interesting approach involving the use of $\beta$-NaGdF4:X\% $\mathrm{Eu}^{3+}$ nanoparticles with poly(acrylic acid) (PAA) surface modification for X-ray luminescence computed tomography (XLCT) has been proposed. XLCT is based on the use of $\mathrm{X}$-ray excitable particles that, when exposed to X-ray, produce luminescence that can be collected by light-based detection systems. XLCT surpasses other imaging techniques in terms of resolution thanks to the use of optical detection without the significant drawback of fluorescence-based approaches like high auto-fluorescence of tissue and low tissue penetration. ${ }^{25}$ However, the major drawback of XLCT is the high toxicity and low stability of the commonly used probes. ${ }^{25}$ Using $\beta-\mathrm{NaGdF}_{4}: \mathrm{X} \% \mathrm{Eu}^{3+}$, Zhang et al. were able to overcome these limitations providing highly biocompatible materials both in vitro and in vivo with optimal XLCT imaging properties. ${ }^{25}$

\section{Magnetic resonance imaging (MRI)}

MRI is a non-invasive imaging approach allowing for highresolution 3D imaging of anatomical regions without the need of potentially damaging radiations (e.g., the ionizing X-rays used for CT). Physical principles at the base of MRI and the detailed description of different acquisition modalities are quite complex. In this section, a short introduction to the MRI method and on the diagnostic potential of the different acquisition modalities adopted in cerebral ischemia are reported and compared to CT. The majority of the section will be focused on innovative nanoplatforms that act as smart contrast agents, able to identify specific cell types (e.g., endothelial cells, $\mathrm{CD}^{+}$cells, and transplanted therapeutic cells), the formation of anatomical structures (e.g., cerebral collaterals), and the detection of the activation of different biological processes (e.g., inflammation and apoptosis) arising during ischemia. Finally, a brief description of the most recent examples of theranostic nanosystems specifically developed for ischemic stroke will be presented (Table 2).

MRI technology exploits an intense magnetic field to induce directional changes of the rotational axis of the protons in the water molecules present in living tissues. More specifically, radiofrequency fields are applied through the patient, and the energy released as the protons realign to the magnetic field are detected by the MRI sensors. The level of released energy, together with the time required by the protons to realign to the magnetic field, provides valuable information revealing the chemical nature of the molecules, allowing to distinguish different tissues (e.g., gray and white matter in the brain), metabolism levels and functions. ${ }^{26,27}$

Concerning ischemic stroke, MRI represents a sensitive and reliable imaging technique for monitoring the localization and the size of the infarcted region, the hypo-perfused tissue, and the presence of the thrombus (which can be treated as previously mentioned, using thrombectomy or thrombolysis). The size of the infarcted tissue is an important clue when estimating the risks of intracranial hemorrhage since this mainly occurs in patients with larger infarcted areas. ${ }^{28}$ Moreover, MRI allows the imaging of the subclinical satellite ischemic lesions, the chronic ischemic changes, and the microbleeds, therefore highlighting important information about the stroke mechanisms and its possible evolution. The presence of microbleeds, as an example, is considered a marker of hemorrhage-prone small vessel disease and is associated with an increased frequency of intracerebral hemorrhage. Comparing to CT, MRI displays superior sensitivity for detecting small symptomatic ischemic lesions, and to discern them from chronic lesions, even when localized in the brainstem and in the cerebellum. ${ }^{29}$ Although characterized by a lower sensitivity for detecting brain ischemia, computed tomographers are widespread, efficient, and readily available diagnostic instruments for emergency situations. CT main advantages with respect to MRI are mainly linked to the faster acquisition times (about 1-2 min for non-enhanced CT; around $10 \mathrm{~min}$ when combining non-enhanced CT with dynamic CT perfusion and CT angiography). In these regards, it is essential to highlight a few specialized centers that recently developed advanced MRI protocols, shortening the imaging time to about $6 \mathrm{~min}$. However, despite this improvement in the imaging protocol, the total time required from the exam prescription to the post-processing data can exceed $30 \mathrm{~min} .{ }^{30}$ An exhaustive review reporting the different MRI acquisition modalities adopted in cerebral ischemia and their comparison with CT imaging has been recently reported elsewhere. ${ }^{16}$

Advanced diagnostic methods able to evaluate the dynamic phenomena occurring during the different phases of the ischemic stroke are crucial for elaborating appropriate and personalized clinical decisions and for improving treatment outcomes. Thanks to the recent development of nanotechnology in the biomedical field, many different MRI detectable nanoplatforms able to target specific cell types, tissues, and the activation of specific physio-pathologic events have been demonstrated on in vivo models of cerebral ischemia (Fig. 2). In this context, superparamagnetic iron oxide nanoparticles (SPIONs) represent a valuable multifunctional theranostic nanoplatform, which can be detected in real-time through magnetic particle imaging thanks to their characteristic relaxation dynamics. ${ }^{31}$ Moreover, SPIONs are considered highly biocompatible, especially when compared to other inorganic nanoparticles, and have already been FDA-approved for the clinical treatment of the anemia associated to chronic kidney disease. ${ }^{32,33}$

The strong diagnostic potential of SPIONs has been recently exploited for the timely visualization of the cerebral collaterals 


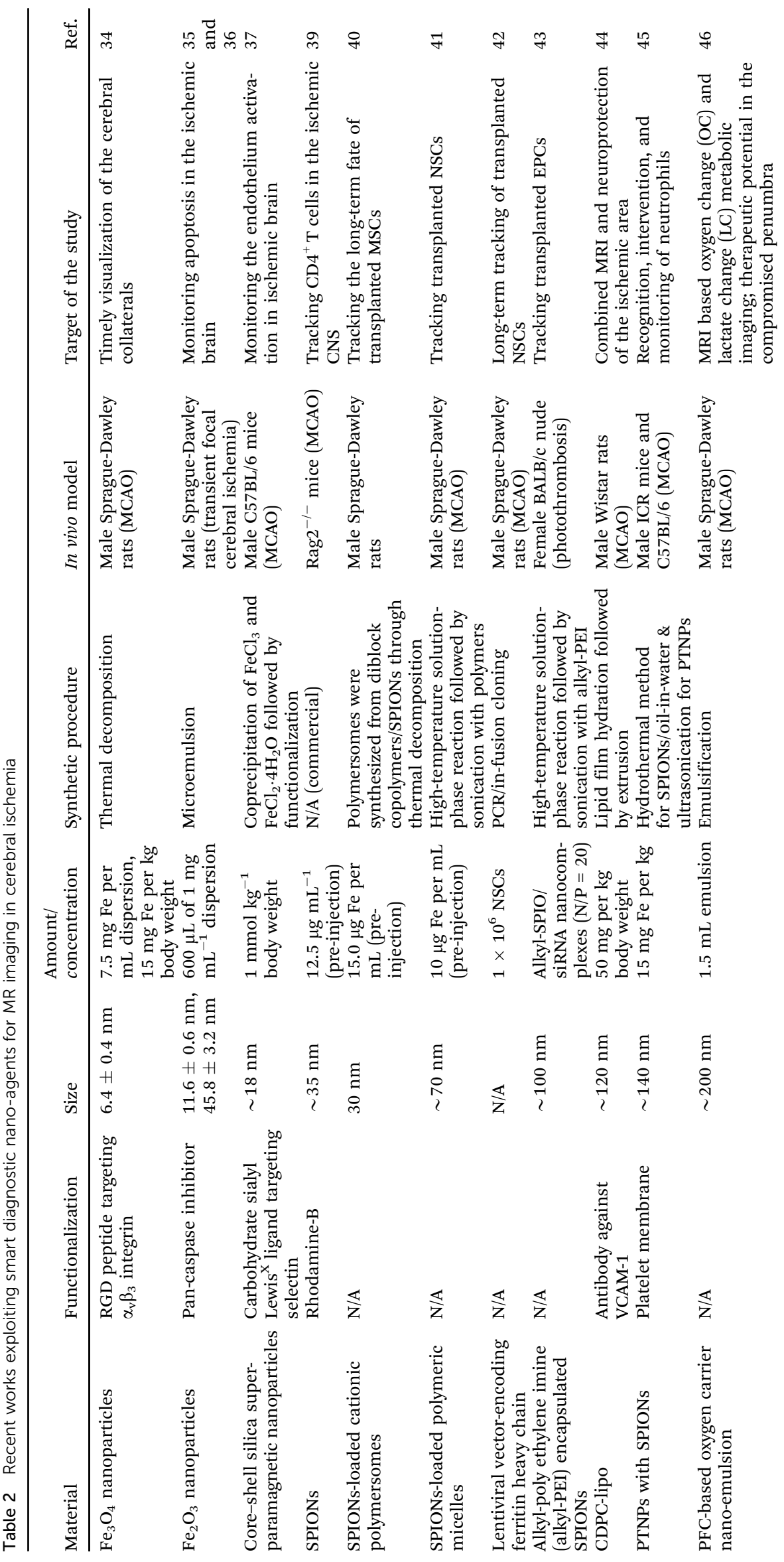



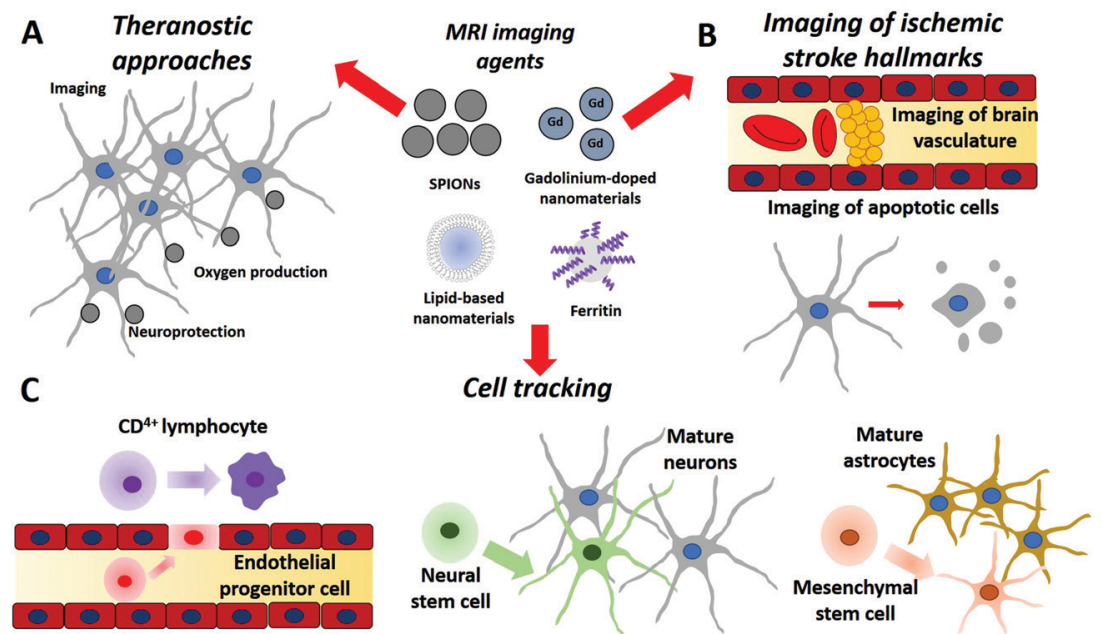

Fig. 2 Applications of various smart nano-agents for (A) theranostics, (B) MRI imaging, and (C) cell tracking on ischemic stroke.

developed during ischemic injury after middle cerebral artery occlusion in rat models. ${ }^{34}$ Leptomeningeal collaterals are small collaterals $(50-400 \mu \mathrm{m})$ developing during the acute phase, and play an essential role in promoting retrograde perfusion of contiguous regions; due to their small size, imaging of these collaterals by CT and MRI is particularly challenging. The possibility of monitoring in real-time the dynamic of these cerebral collaterals can be particularly relevant for undertaking strategic clinical decisions, for analyzing collateral changes during therapy, and for evaluating the hemorrhage risks after reperfusion. Binding specificity to cerebral collaterals has been obtained by targeting the $\alpha_{v} \beta_{3}$ integrin, which is highly expressed by human brain microvascular endothelial cells and plays a critical role in post-ischemic angiogenesis. ${ }^{34}$ Specifically, modified PEG-coated $\mathrm{Fe}_{3} \mathrm{O}_{4}$ magnetic nanoparticles with $6.4 \pm$ $0.4 \mathrm{~nm}$ diameter were covalently functionalized with a targeting peptide sequence (e.g., Arg-Gly-Asp-Cys) via click reaction. The obtained nanoprobe $\left(\mathrm{Fe}_{3} \mathrm{O}_{4}-\mathrm{RGD}\right)$ showed optimal targeting specificity and allowed to monitor the collateral dynamics upon reperfusion: the cerebral collaterals rapidly appeared during the acute phase of ischemia, quickly disappeared upon reperfusion (obtained by removing the occlusion $2 \mathrm{~h}$ after surgery), and did not recover even after $24 \mathrm{~h}$. These observations indicate a relevant time window for encouraging antegrade blood flow to lower the risk of hemorrhage.

In addition to cerebral collateral monitoring, SPIONs-based nano-tools have also been designed to noninvasively identify and study specific phenomena occurring in the ischemic brain, like apoptosis, inflammation, and endothelial activation. Concerning apoptosis, a specific nanoprobe consisting of $\mathrm{Fe}_{2} \mathrm{O}_{3}$ magnetic nanoparticles functionalized with a pan-caspase inhibitor has already been reported. ${ }^{35,36}$ The specific targeting of this nanoprobe to the apoptotic cells of the ischemic region was demonstrated by histologic analysis and TUNEL staining. Furthermore, the accumulation of this targeted contrast agent was detected by MRI in terms of reduction of the $\mathrm{T} 2{ }^{*}$ relaxation time. No probe accumulation and no $\mathrm{T} 2 *$ reduction were instead found in the non-ischemic regions. The early endothelial inflammation upon ischemic stroke has been alternatively monitored by using modified SPIONs designed to target selectin, ${ }^{37}$ a group of endothelial transmembrane proteins involved in leukocyte adherence to blood vessels during inflammation. In this work, amino-functionalized $\mathrm{Fe}_{3} \mathrm{O}_{4}$ core silica (Si) shell nanoparticles with an $18 \mathrm{~nm}$ size were conjugated to the carbohydrate sialyl Lewis ${ }^{\mathrm{X}}$ (SX@MNPs), a well-known selectin ligand. The nanoparticles efficiently accumulated in the brain vasculature of a clinically relevant animal model of stroke.

However, in this work, authors also detected an efficient accumulation of the non-functionalized particles, with exposed hydroxyl groups (HO@MNPs) on their surface, in the ischemic area; although further investigations will be required to comprehend the mechanisms of this selectin-independent targeting effect, naked particles appeared to be a plausible contrast agent as well, able to accumulate at the ischemic vasculature. A detailed review of micro-size iron oxide particles for molecular MRI of endothelial activation in the brain can be found elsewhere. $^{38}$

SPIONs have also been exploited as an MRI contrast agent to non-invasively track different cell types in the context of cerebral ischemia. As an example, researchers intravenously injected $\mathrm{CD}^{+} \mathrm{T}$ cells previously incubated with rhodamine-B labeled SPIONs in order to study the role of lymphocytes in the inflamed central nervous system during ischemic injury. ${ }^{39}$ This approach allowed the tracking of lymphocytes in the brain, liver, and spleen for days through MRI and Xenogen in vivo imaging system (IVIS). The synergic combination of the two techniques conferred non-invasiveness and durability to the imaging, allowing them to perform long-term tracking of $\mathrm{CD}^{+}$ $\mathrm{T}$ cells in vivo, avoiding the use of radioactive materials. With similar approaches, different transplanted cell types, which are considered promising candidates for the treatment of stroke, have been monitored through MRI. In this regard, mesenchymal stem cells (MSCs), thanks to their immunomodulatory, immunedepressive, and multi-potential properties, may represent a 
valuable tool in stroke therapy. In recent work, transplanted green fluorescent protein (GFP)-expressing MSCs pre-incubated with SPIONs-loaded polymersomes were used to analyze migration, long-term fate, and survival of MSCs. ${ }^{40}$ Interestingly, although treatment with MSCs was accompanied by a reduction of the infarct region and by an improved functional outcome, most transplanted GFP-MSCs did not survive at 8 weeks after grafting (number of grafted cells sharply decreased at 2 weeks after transplant). Moreover, only a small percentage of the survived cells differentiated into astrocytes, but not into neurons. For these reasons, it was hypothesized that the therapeutic effects of MSCs in ischemic stroke might be mostly mediated by the secretion of paracrine factors, rather than cell replacing. The incubation of GFP-MSCs with SPIONs-loaded polymersomes did not induce adverse effects on cell viability, oxidative stress, and apoptosis, demonstrating the safety of the labeling approach. Therefore, the scarce survival of transplanted MSCs could not be associated with the nanoparticle uptake. Most importantly, in this work, the changes in MRI hypo-intense signal reflected the number of viable cells, with a significant decrease in the signal at 2 weeks after grafting. A lower percentage of GFP-MSCs were found migrating from the transplantation site, and this result was confirmed by histology; therefore, magnetic particle imaging non-invasively provided valuable information on survival, homing, and migration of transplanted cells.

By exploiting SPIONs-loaded polymeric micelles, the same group also tracked neural stem cells (NSCs) after transplantation in rats with middle cerebral artery occlusion. ${ }^{41}$ Similar to what was observed for MSCs, MRI hypo-intense regions were able to reliably identify and track transplanted cells in the infarcted hemisphere. The results were confirmed by comparing MRI with histological data. Alternatively to SPIONs, the overexpression of the iron-storing ferritin heavy chain (FTH) represents a valuable contrast agent for MRI and has been exploited for tracking NSCs after transplantation in rats with an ischemic brain. ${ }^{42}$ The overexpression of the FTH is accompanied by an upregulation of ferritin receptors and a consequent iron overload in the cells. MRI hypo-intense signal associated with the presence of FTH- and GFP-expressing NSCs was assessed over a period of 6 weeks. Also, in this work, signal localization by MRI and fluorescence imaging were subsequently compared. Cell migration was not detected, and a slight gradual decrease of NSC signal was found along the 6 weeks, probably due to the progressively decreased survival of grafted cells. The infarct volume and behavioral performances improved in transplanted rats with respect to controls, both in case of transduced and non-transduced NSCs. This result is particularly important and indicates that FTH-overexpressing NSCs maintain their therapeutic potential.

As a last example of the recent literature, amphiphilic low molecular weight alkyl-poly(ethylene imine) (alkyl-PEI) encapsulated SPIONs have been used to track transplanted endothelial progenitor cells (EPCs) in a photo-thrombotic mouse model of focal ischemic stroke. ${ }^{43}$ Particularly noteworthy of this nanotechnology approach is the use of small interference RNA (siRNA) complexed to the alkyl-PEI-SPIONs.
This smart nano-agent allowed to silence the hypoxia-inducible factor (HIF)-prolyl hydroxylase 2 (PHD2), and consecutively promoted the migration and survival ability of the EPCs. Thanks to this approach, the nanoplatform not only operated as a nanoprobe for the non-invasive monitoring of the transplanted cells but also enhanced its therapeutic potential for the treatment of ischemic stroke.

Finally, innovative smart theranostic nano-platforms, which are coupled to MRI and are not based on SPIONs, have been recently proposed. A first exciting example consists of citicoline-loaded liposomes (CDPC-lipo). ${ }^{44} \mathrm{CDPC}$ is a biological molecule, an intermediate generated during the synthesis of phosphatidylcholine from choline. It is well-known for its potential neuroprotective effects but also displays an inherent chemical exchange saturation transfer (CEST) MRI signal. Taking advantage of its combined diagnostic and therapeutic functions, the delivery of CDPC-lipo was monitored and quantified in a rat model of transient cerebral ischemia. Intra-arterially administrations of CDPC-lipo resulted in their preferential accumulation in the ischemic area, probably due to the local disruption of the BBB. This theranostic approach, which does not require the use of any inorganic material as a contrast agent, may pave the way to its rapid translation to the clinical practice. Indeed, liposomes represent highly-stable biocompatible carriers already exploited in different FDA-approved nanoformulations for BBB crossing. Moreover, the functionalization of liposomes can provide further selectivity and targeting abilities to these nanostructures. To this aim, CDPC-lipo has been conjugated to an antibody for explicitly targeting the vascular cell adhesion molecule 1 (VCAM-1), an adhesion protein that is expressed by endothelial cells and is strongly upregulated in association with neuro-inflammation in ischemic stroke. VCAM-1-targeted CDPClipo preferentially accumulated in the ischemic regions with respect to the control liposomes, which were instead conjugated with nontargeted IgG antibodies.

Platelet-mimetic nanoparticles (PTNPs) co-loaded with piceatannol and superparamagnetic iron oxide nanoparticles have been exploited in a multi-modal IVM and MRI approach for the detection and the treatment of acute ischemic stroke. Cy5 stained PTNP ability to target inflammatory neutrophils in vivo was assessed using real-time fluorescence IVM, while SPIONs loaded inside the nanostructures acted like a $\mathrm{T}_{2}$ contrast agent for MRI detection. This work represents a good example of a multifunctional nanostructure able to act as a labeling agent in two techniques used to provide information at two different levels: on one side, IVM provided insight about cellular localization of the particles, on the other one MRI provides useful information at whole organ level. ${ }^{45}$

The last example of a label-free nano theranostic platform for cerebral ischemia has been recently proposed for the reliable identification and treatment of the hypo-perfused, metabolically active ischemic penumbra tissue, ${ }^{46}$ the functional rescue of which significantly improves the clinical outcome. This nanoplatform is based on perfluorocarbon (PFC) oxygen carrier nanoemulsion (200 $\mathrm{nm}$ particle size), coupled with innovative MRI approaches allowing for oxygen change (OC) and lactate change (LC) metabolic imaging. 
Following the administration of the Oxycyte ${ }^{\circledR}$ (O-PFC) and applying hyperoxia, metabolically active penumbra was monitored in rat models of acute stroke. Moreover, the first proofs of the therapeutic action following acute ischemic stroke were collected by an analysis of the lesion growth. However, the potential theranostic effects of this approach on patients will soon be examined in a clinical trial (NCT03463551; trial submitted on March 2018). Specifically, the safety and tolerability of 3 doses of the PFC-based oxygen carrier and supplemental oxygen will be tested on patients with ischemic stroke ( $<72 \mathrm{~h}$ after onset). MRI imaging of the infarct volume will also be monitored, and obtained results will be compared to the placebo group.

Concluding, MRI is a valuable diagnostic tool for cerebral ischemia and can be successfully combined with smart nanotechnology-based probes for targeting specific cell types, for a timely analysis of complex events occurring during ischemia (formation of collaterals, apoptosis, inflammation), for monitoring the metabolism in the hypo-perfused regions of the ischemic penumbra, and for tracking the fate of therapeutic cells. The diagnostic and therapeutic potential of these MRI detectable smart nano-devices have been recently demonstrated on in vivo models, but only exceptionally clinical trials have been carried out to study their actual relevance in the clinical context. Concerning the SPIONs, they have been included in clinical trials using MRI for the assessment of myocardial infarction (NCT01995799), carotid atherosclerosis (NCT01674257), and inflammation of the central nervous system (NCT00659776) and of the heart (NCT02319278). However, only a few results are available on these studies yet. We are confident that, in the near future, many more nano-diagnostic approaches will be tested on in vivo models of cerebral ischemia, and will provide vital information for the treatment of stroke patients.

\section{Positron emission tomography (PET)}

PET is one of the first imaging techniques that were used to image the brain penumbra. Its operating principle is based on the detection of radioactive materials called radiotracers (e.g., F-18 fluorodeoxyglucose, ${ }^{18} \mathrm{~F}$-FDG) and can provide information on the biochemical processes at a cellular level. With respect to other nuclear imaging techniques, PET is not detecting the amount of the administered radiotracers in the body tissue, but the tissue metabolic activity, since the uptake of the tracer is related with the localized glucose uptake. Although PET is a fast technique with the ability to provide quantitative data, two of its significant drawbacks include radiation and high cost.

PET, as other imaging techniques, has been used either alone or in combination with MRI and/or CT. Due to its high sensitivity, it is used for the investigation of a variety of brain disorders such as Parkinson's disease, Alzheimer's disease, epilepsy, and others. In the case of ischemic stroke, PET has been used for the study of the infarct volume as well as of other abnormalities that take place during the ischemia/reperfusion cascade. Several examples of the application of PET in cerebral ischemia are summarized in Table 3. For example, the role of the toll-like receptor 4 (TLR4) in the post-ischemic stroke inflammation and neurogenesis was studied using two different radiotracers, $3^{\prime}-\left[{ }^{18} \mathrm{~F}\right]$ fluorothymidine (FLT) and 1-(2-chlorophenyl)$N$ - $\left[{ }^{11} \mathrm{C}\right]$ methyl- $N$-(1-methyl propyl)-3-isoquinoline carboxamide $\left(\left[{ }^{11} \mathrm{C}\right] \mathrm{PK} 11195\right) .{ }^{47}$ The combination of these radiotracers allowed the observation of cell proliferation and inflammation through the translocation protein (TSPO) expression in TLR4 $4^{+/+}$and TLR4 ${ }^{-1-}$ mice. Additionally, it revealed time-dependent neurogenesis and inhibition of inflammation associated with the lack of TLR4. MRI was also used in this study to investigate the extent of brain infarction. Although $\left[{ }^{11} \mathrm{C}\right] \mathrm{PK} 11195$ is a standard tracer able to quantify the TSPO binding affinity to the ischemic tissue, it can also be used in glioma. ${ }^{48}$ It has to be noted that other tracers with a higher TSPO-binding affinity compared to $\left[{ }^{11} \mathrm{C}\right] \mathrm{PK} 11195$, like the 2-(5-(6-fluoropyridin-3-yl)-2-oxobenzo [d]-oxazol-3(2H)-yl)- $N$-methyl$\mathrm{N}$-phenylacetamide (FODMP), have also been reported. ${ }^{48}$

Tracers that measure the TSPO binding potential have also been used in combination with tracers for microglia activation. ${ }^{49}$ In this reported work, $\left[{ }^{11} \mathrm{C}\right](R) \mathrm{PK} 11195$ was combined with the cannabinoid receptor type $2\left(\mathrm{CB}_{2}\right),\left[{ }^{11} \mathrm{C}\right] \mathrm{NE} 40$. It was found that the $\left[{ }^{11} \mathrm{C}\right] \mathrm{NE} 40$ binding potential $\left(\mathrm{BP}_{\mathrm{ND}}\right)$ was higher in the ischemic tissue compared to the non-ischemic one. This increase, along with the higher immune-histological expression of $\mathrm{CB}_{2}$ (microglia marker), suggested the potential role of early-activated microglia in the neuroprotective process. Notably, no difference was observed for the $\left[{ }^{11} \mathrm{C}\right](R) \mathrm{PK} 11195$ tracer.

Another factor that needs to be taken into consideration before and after ischemic stroke is the formation of atherosclerotic plaque in the carotid artery. ${ }^{50,51}$ It has been shown that this formation and the subsequent inflammation can be detected using the ${ }^{18}$ F-FDG tracer, ${ }^{51}$ the uptake of which can be used as a marker of unstable carotid plaque that can lead to a stroke. One of the performed clinical investigations ${ }^{51}$ demonstrated a relationship between the uptake of the ${ }^{18}$ F-FDG tracer and the prediction of future recurrent stroke post-PET. This resulted in better identification of patients that need revascularization of the carotid artery. The formation of $\beta$-amyloid after ischemic stroke has also been studied using a Pittsburgh compound B $\left({ }^{11} \mathrm{C}-\mathrm{PiB}\right),{ }^{52}$ but the results did not show any correlation between the deposition of $\beta$-amyloid and the ischemic attack.

It is well known that during ischemic stroke, the brain is subjected to microstructural changes (e.g., BBB disruption) that may further influence other areas of the brain besides the core and the penumbra. Since these changes cannot be observed using MRI, the PET-tracer ${ }^{18} \mathrm{~F}$-THK-5351 was recently developed. ${ }^{53,54}$ The tracer can bind to the enzyme monoamine oxidase $\mathrm{B}$ (MAO-B), which is highly expressed in reactive astrocytosis, a neuro-inflammatory phenomenon. ${ }^{53}$ Using this tracer axonal demyelination or degeneration was observed in both close and remote areas around the stroke. These structural changes were verified using diffusion tensor imaging (DTI) (Fig. 3).

\section{Magnetic particle imaging (MPI)}

MPI is a new and emerging tomographic technique that is based on the magnetic properties of superparamagnetic iron 
Table 3 Recent works exploiting smart diagnostic nano-agents for PET imaging in cerebral ischemia

\begin{tabular}{|c|c|c|c|c|c|c|c|}
\hline Material & $\begin{array}{l}\text { Functionali- } \\
\text { zation }\end{array}$ & Size & $\begin{array}{l}\text { Amount/ } \\
\text { concentration }\end{array}$ & Synthetic procedure & In vivo model & Target of the study & Ref. \\
\hline $\begin{array}{l}{\left[{ }^{18} \mathrm{~F}\right] \text { FLT and }} \\
{\left[{ }^{11} \mathrm{C}\right] \mathrm{PK} 11195}\end{array}$ & $\mathrm{~N} / \mathrm{A}$ & $\mathrm{N} / \mathrm{A}$ & $20 \mathrm{MBq}$ per animal & $\begin{array}{l}\text { Methylation }(R)-N- \\
\text { desmethyl-PK11195 }\end{array}$ & $\begin{array}{l}\text { Male C57BL/10ScNJ } \\
\left(\mathrm{TLR} 4^{-/-}\right) \text {and } \\
\text { C57BL/10 J }\left(\mathrm{TLR}^{+/+}\right) \\
(\mathrm{MCAO})\end{array}$ & $\begin{array}{l}\text { TLR4 on cell } \\
\text { proliferation, } \\
\text { neuro-inflammation, } \\
\text { TSPO expression }\end{array}$ & 47 \\
\hline${ }^{18}$ F-FODMP & N/A & N/A & $\begin{array}{l}52 \mathrm{MBq}, 0.7 \mathrm{nmol} \text { or } \\
20 \mathrm{MBq}, 0.054 \mathrm{nmol} \text {, } \\
\text { depending on the } \\
\text { analog }\end{array}$ & $\begin{array}{l}\text { Reaction of } \\
\text { desmethyl precursor } \\
\text { with }\left[{ }^{11} \mathrm{C}\right] \mathrm{MeI}\end{array}$ & $\begin{array}{l}\text { Male ddY and } \\
\text { Sprague-Dawley rats } \\
\text { (MCAO) }\end{array}$ & TSPO expression & 48 \\
\hline $\begin{array}{l}{\left[{ }^{11} \mathrm{C}\right](R) \mathrm{PK} 11195 \text { and }} \\
{\left[{ }^{11} \mathrm{C}\right] \mathrm{NE} 40}\end{array}$ & $\mathrm{~N} / \mathrm{A}$ & N/A & $48 \mathrm{MBq}$ per kg & $\mathrm{N} / \mathrm{A}$ & $\begin{array}{l}\text { Sprague-Dawley rats } \\
\text { (photothrombosis) }\end{array}$ & $\begin{array}{l}\text { TSPO and CB2 } \\
\text { expression }\end{array}$ & 49 \\
\hline $\begin{array}{l}{ }^{18} \text { F-fluoride or } \\
{ }^{18} \text { F-FDG }\end{array}$ & $\mathrm{N} / \mathrm{A}$ & $\mathrm{N} / \mathrm{A}$ & $200 \mathrm{MBq}$ per animal & $\mathrm{N} / \mathrm{A}$ & N/A & $\begin{array}{l}\text { Carotid plaque } \\
\text { inflammation }\end{array}$ & $\begin{array}{l}50 \\
\text { and } 51\end{array}$ \\
\hline${ }^{11} \mathrm{C}-\mathrm{PiB}$ & $\mathrm{N} / \mathrm{A}$ & N/A & $370 \mathrm{MBq}$ per animal & $\mathrm{N} / \mathrm{A}$ & N/A & Presence of $\beta$-amyloid & 52 \\
\hline${ }^{18} \mathrm{~F}-\mathrm{THK}-5351$ & $\mathrm{~N} / \mathrm{A}$ & $\mathrm{N} / \mathrm{A}$ & $\begin{array}{l}378 \pm 17 \mathrm{MBq} \text { per } \\
\text { animal }\end{array}$ & $\begin{array}{l}\text { Prepared from } \\
\text { tosylated precursors }\end{array}$ & N/A & $\begin{array}{l}\text { Investigation of } \\
\text { post-ischemic gliosis } \\
\text { (affinity to MAO-B) }\end{array}$ & 53 \\
\hline
\end{tabular}
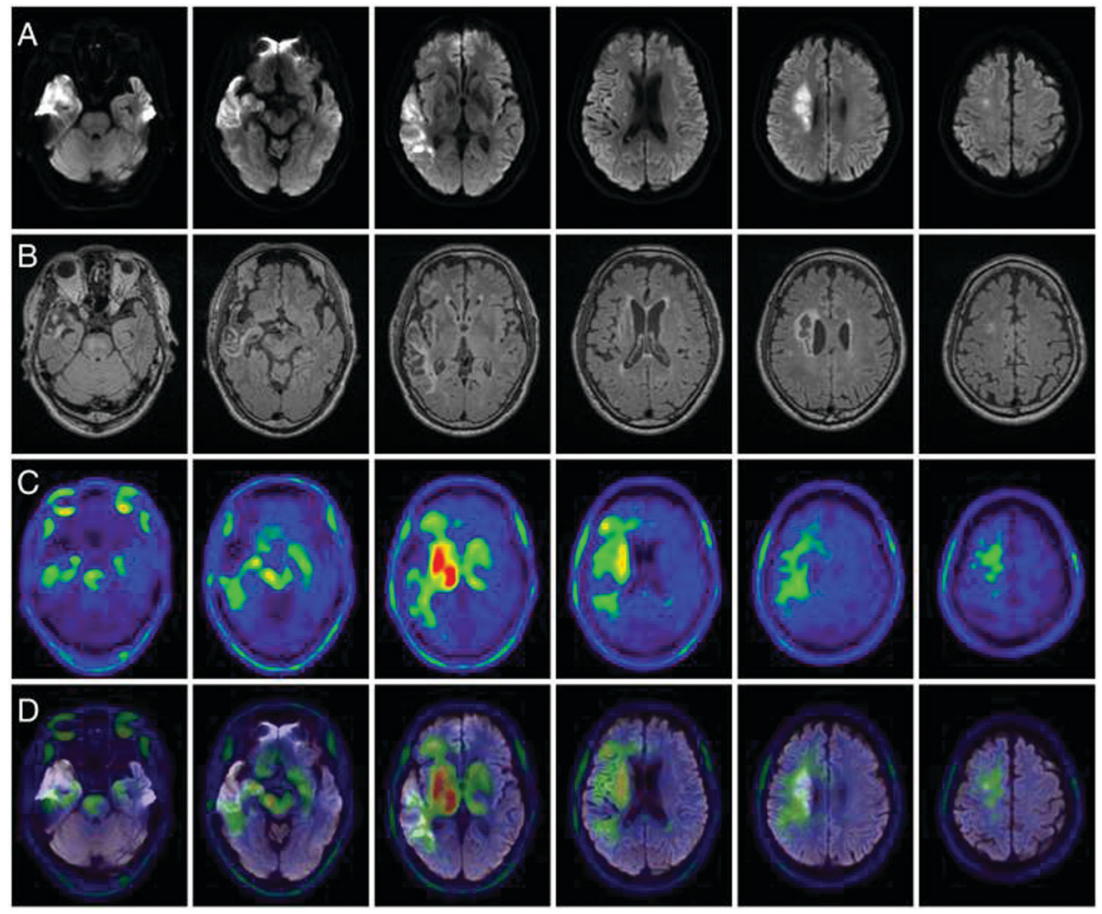

${ }^{18}$ F THK-5351 SUVR

0

4

Fig. $3{ }^{18} \mathrm{~F}$-THK-5351 retention patterns in an ischemic stroke patient. (A) The acute ischemic location on diffusion-weighted imaging (DWI). (B and C) FLAIR images and ${ }^{18} \mathrm{~F}-\mathrm{THK}-5351$ PET images taken 3 months after stroke, respectively. (D) The fused DWI and ${ }^{18} \mathrm{~F}-\mathrm{THK}-5351$ PET images. Common offtarget binding of the $18 \mathrm{~F}-\mathrm{THK}-5351$ is observed in the bilateral striatum, thalamus, and brainstem. Additionally, the ${ }^{18} \mathrm{~F}-\mathrm{THK}-5351$ retention is asymmetrically increased in the remote and peri-infarct areas and decreased in the infarct core. Adapted with permission from Huang et al. ${ }^{53}$ under the creative commons license CC BY 4.0 .

oxide nanoparticles (SPIONs) ${ }^{31}$ under an oscillating magnetic field. In contrast to computed tomography and magnetic resonance imaging, MPI is a low-radiation method with a high spatiotemporal resolution, able to trace and quantify very low amounts of the tracer (from nano-molar to the pico-molar range), ${ }^{55,56}$ and without the background noise of the tissue. This high sensitivity, which is comparable to PET and SPECT, as well as the ability of very fast (few milliseconds) and fourdimensional imaging, render this technique suitable for the live monitoring of various diseases including ischemic stroke. ${ }^{55,56}$

Because MPI is a technique at its early stages, there are very few reported studies ${ }^{56}$ where it has been used. Nevertheless, one of the first works that demonstrated the imaging capabilities of this method was on the detection of ischemic stroke in a mouse model. ${ }^{31}$ More specifically, the main goal of this work was the detection of perfusion deficits, that would allow the discrimination between the infarcted core and the penumbra. To achieve 
Table 4 Recent works exploiting smart diagnostic nano-agents for MP imaging in cerebral ischemia

\begin{tabular}{|c|c|c|c|c|c|c|c|c|}
\hline Material & $\begin{array}{l}\text { Functionali- } \\
\text { zation }\end{array}$ & Size & $\begin{array}{l}\text { Amount/ } \\
\text { concentration }\end{array}$ & $\begin{array}{l}\text { Synthetic } \\
\text { procedure }\end{array}$ & In vivo model & $\begin{array}{l}\text { Clinical } \\
\text { study }\end{array}$ & Target of the study & Ref. \\
\hline Perimag & $\mathrm{N} / \mathrm{A}$ & N/A & $\begin{array}{l}\text { Various } \\
\text { concentrations }\end{array}$ & Commercial & $\mathrm{N} / \mathrm{A}$ & N/A & $\begin{array}{l}\text { Applicability of a } \\
\text { human-sized MPI } \\
\text { scanner }\end{array}$ & 56 \\
\hline LS-008 & N/A & $65 \mathrm{~nm}$ & $46 \mathrm{mmol} \mathrm{Fe}$ per $\mathrm{L}$ & Commercial & $\begin{array}{l}\text { C57BL/6 Mice } \\
\text { (MCAO) }\end{array}$ & N/A & $\begin{array}{l}\text { Detection of perfusion } \\
\text { deficits }\end{array}$ & 31 \\
\hline $\begin{array}{l}\text { PMAO-PEG-coated } \\
\text { LS-008 and lab- } \\
\text { made SPIONs }\end{array}$ & N/A & $\sim 60-80 \mathrm{~nm}$ & $\begin{array}{l}\sim 70-90 \mu \mathrm{g} \mathrm{Fe} \\
\text { per } \mathrm{mL}\end{array}$ & $\begin{array}{l}\text { Thermolysis } \\
\text { reaction for the } \\
\text { SPIONs and } \\
\text { phase transfer } \\
\text { for the coating }\end{array}$ & $\begin{array}{l}\text { Female CD-1 mice } \\
\text { (model N/A) }\end{array}$ & N/A & $\begin{array}{l}\text { Evaluation of PEG } \\
\text { coating in the blood } \\
\text { circulation of the NPs }\end{array}$ & 57 \\
\hline
\end{tabular}

this, the authors of the study investigated in vivo the commercial tracer LS-008, which allowed them to acquire information on the cerebral vasculature, as well as details of the perfusion and on stroke. Further findings, including the differentiation of the arterial and venous vessel and the estimation of the heart rate, were also presented. Although LS-008 was proved to be a good tracer to demonstrate the capabilities of MPI, its short circulation times are an obstacle to its robust use. To overcome this limitation, LS-008 was coated with a polymer that combined poly(maleic anhydride-alt-1-octadecene) (PMAO) with PEG. ${ }^{57}$ The coating improved the colloidal stability and the subsequent blood circulation times (up to $3.5 \mathrm{~h}$ ) of the tracer, suggesting its potential use to cardio and cerebrovascular diseases, as well as to solid tumors.

A summary of the reported works where MPI is used is presented in Table 4.

The continuous development of MPI and the need for improving the current imaging techniques led to the development of a human-sized MPI (Fig. 4) with high sensitivity, able to be used in stroke and intensive care units. ${ }^{56}$ Although being a relatively new technology, MPI holds great potential as an alternative ultrafast and high-resolution imaging method for clinical applications. ${ }^{12}$

\section{Intravital microscopy (IVM)}

IVM represents an incredible tool to investigate biological structures at the cellular level of a living organism. However, IVM is still mostly a research tool more than a clinical diagnosis procedure, and the reasons for this are several. Firstly, the commonly used lasers and other light sources have inferior penetration potential when compared to other techniques like CT or MRI, while secondly, IVM is a highly time-consuming technique that requires expensive instruments and direct access to the brain. Nevertheless, the most significant advantage of IVM is the unmatched power of resolution that can grant information not only on tissues but even on cellular or sub-cellular levels. ${ }^{58}$ For the application of IVM in ischemic stroke and the imaging of the brain and its vasculature, three
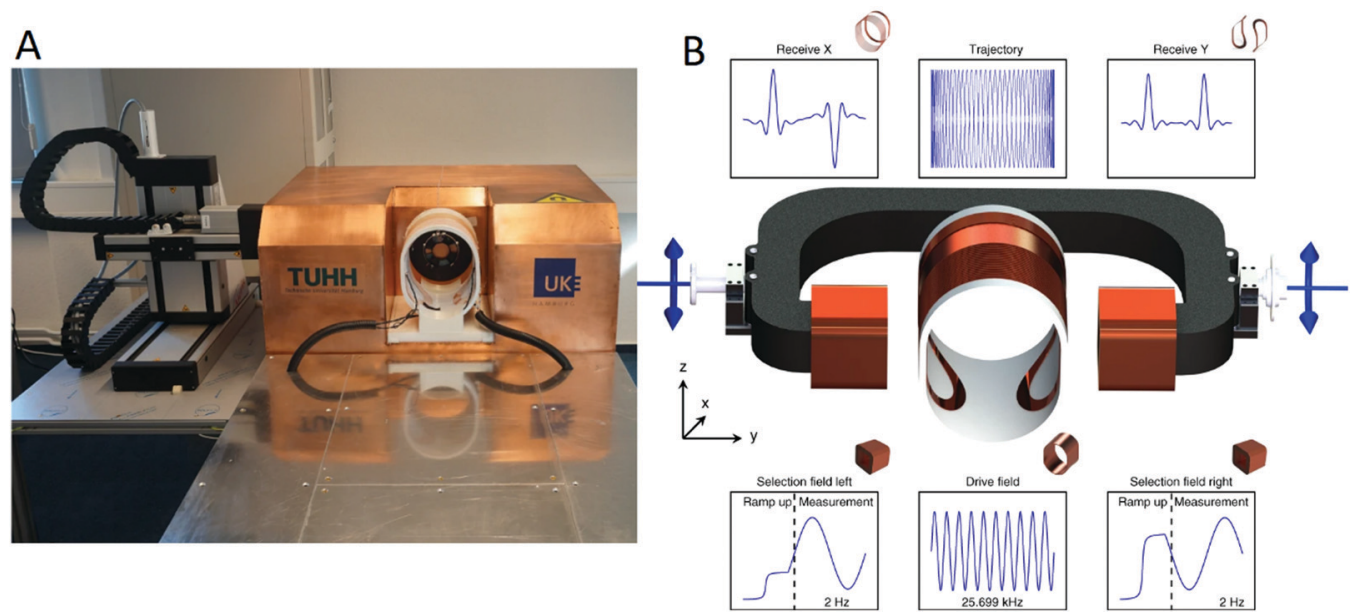

Fig. 4 (A) Depiction of a human-sized magnetic particle imager for brain applications. The system-calibration robot is placed to the left of the imager (left). (B) Scanner concept; the central coil is used as a drive-field generator with a specific frequency and amplitude. The cross-section is formed by two half circles connected by straight parts forming an ellipsoid-like shape. The selection-field coils are driven by sinusoidal currents with opposite signs superimposed by an offset current. This generates a filed-free point (FFP) oscillating on the $y$-axis in-between the selection-field coils. The superposition of the drive-field and the selection-field generates a Cartesian-like FFP trajectory covering a specific field-of-view (FOV) within the XY-plane. The particle response is received by dedicated coils in $x$-direction and $y$-direction. Adapted with permission from Graeser et al. ${ }^{56}$ under the creative commons license CC BY 4.0 . 

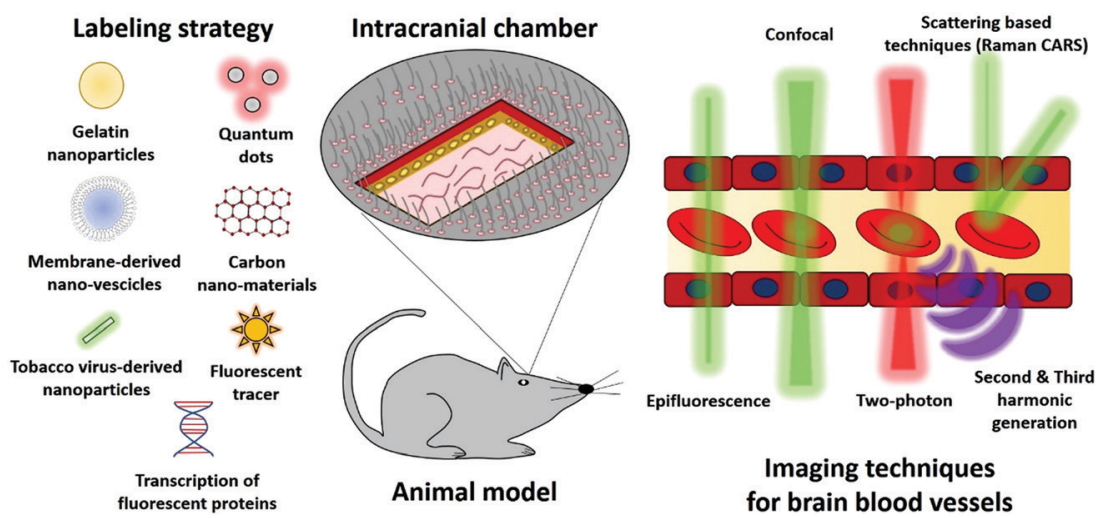

Fig. 5 Labeling strategies and imaging techniques used during the intravital microscopy on an animal model bearing an intracranial chamber.

main points need to be considered in order to have the optimal imaging conditions. These are the accessibility of the brain, the type of microscopy technique to use, and which eventual labeling-strategy to perform (Fig. 5). One of the significant challenges of IVM techniques is to pass through the skull, and so the application of an intracranial chamber is usually the preferred strategy. ${ }^{59}$ Animals with intracranial chambers have shown little to no adverse effects even after months from implant. ${ }^{60}$ Several factors need to be taken into account when choosing the optimal microscopy technique for IVM applications including, the time required for image acquisition, the spatial depth of the biological structure of interest, and if a label strategy is required. Commonly available wide-field epifluorescence microscopes have the advantage of low cost and rapid acquisition but are limited from the low penetration depth, a relatively high signal background, and low spatial resolution.

Confocal microscopy overcomes the limitations of epifluorescence-based instruments due to its ability to acquire information from single spatial spots limiting the signal derived from the emission of off-focus specimens, significantly increasing spatial resolution and Signal-to-Noise ratio. ${ }^{60}$ Confocal microscopy is also able to reduce both photo-bleaching and eventual photo-induced tissue damage drastically. If the tissue of interest is in a range of $50-100 \mu \mathrm{m}$, confocal microscopy is a viable technique for IVM applications. ${ }^{60}$ However, in order to visualize most biological structures, including brain vasculature, microscopy techniques able to perform deeper imaging are almost mandatory, and so, the preferred strategy for IVM is the two-photon fluorescence microscopy/imaging (TPFM or TPFI).

In two-photon microscopy, two low-level energy photons are exploited to provoke a higher energy electronic transition in fluorescence molecules. ${ }^{61}$ Usually, high wavelength lasers (Deep red or Near infra-red) are used in order to increase light penetration and to reduce the scattering from the tissues. ${ }^{61}$ The main advantages of the two-photon microscopy are lower photo-bleaching and tissue damage levels, and a far higher penetration potential (up to $1 \mathrm{~mm}$ ) in optimal conditions. ${ }^{62}$ It is of pivotal importance to underline that, even if two-photon microscopy can perform imaging up to ten times deeper than other fluorescence techniques, $1 \mathrm{~mm}$ is still very limited when compared with the size of the brain. Most two-photon imaging set-ups are also able to detect second harmonic signals (SHG), that are generated by the substitution of two photons with a third photon at half the wavelength and are commonly used to provide label-free imaging of biological structures. ${ }^{63,64}$ Two-photon microscopies set up can also be used for third-harmonic generation (THG) approaches. THG results when the summed energy of three incoming photons is converted into a single one with triple energy and one-third of the wavelength. ${ }^{65}$ Similarly to SHG, THG has been proven to be a highly efficient tool for the label-free imaging of brain tissues. ${ }^{66}$

With the exception of SHG and THG based microscopy, all the previously mentioned techniques require the labeling of the tissue or biological structure of interest. The easiest way to stain the vasculature of the brain consists of the injection of fluorescent molecules like fluorescent dextran, which is commonly used both for visualizing brain blood vessels and assesses the integrity of the blood-brain barrier through permeability measurements in vivo. ${ }^{67,68}$ Other staining strategies include the use of monoclonal antibodies that grant more specificity and functional information. For example, monoclonal anti CD40 antibodies conjugated with cyanine5.5 (cy5.5) has been showed to study inflammatory pathways in ischemic mice. ${ }^{69}$ Most commonly, animals genetically engineered to express fluorescent proteins (usually GFP) in specific organs or cell types are used for in vivo microscopy applications. For example, transgenic mice expressing fluorescent proteins at the level of microglia, polymorphonuclear neutrophils granulocytes, astrocytes, and even intracellular structures like mitochondria have been used in IVM studies of ischemic stroke. ${ }^{70-72}$

We already mentioned some label-free IVM techniques like SHG and THG; other label-free IVM techniques have been used for in vivo studies like coherent anti-Stokes Raman scattering (CARS) $^{73,74}$ and surface-enhanced Raman spectroscopy (SERS). ${ }^{75}$ Although these techniques have provided useful insight into brain imaging, their exploitation in IVM based approaches concerning ischemic brain is still somewhat limited. ${ }^{76}$ The applicability of nanomaterials in IVM-based approaches has mainly been investigated. IVM has proven an irreplaceable tool to investigate the nanomaterials' targeting efficiency and the interaction with biological structures in vivo. On the other hand, 
ad hoc fluorescent nanomaterials can be fabricated and used as a labeling agent for IVM.

Historically, quantum dots (QDs), thanks to their exceptional fluorescent properties, have been vastly used in IVM studies. ${ }^{77-79}$ QDs are semiconductor nanocrystals with size- and compositiondependent fluorescent properties, that can be easily tuned by synthesis parameters. ${ }^{79}$ QDs have found application as tracers in several ischemic stroke-related studies. As an example, QD800 has been used to mark bone marrow stromal cells (BMSC) subsequently grafted into the infarcted brain of animals. Thanks to its NIR emitting fluorescence, QD800 granted the possibility to trace the grafted cells even after 8 weeks from implantation. ${ }^{80-82}$ Different QDs-based nanostructures have been successfully exploited as a marker for In vivo brain imaging, ${ }^{83}$ like in the case of QDs embedded in poly(ethylene glycol)-poly(lactic acid) nanoparticles functionalized with wheat germ agglutinin (WGA-QDs-NP). ${ }^{84}$ One primary concern and the most significant limiting factor to the use of QDs is related to their biocompatibility, and it has also been reported how high concentration of QDs can lead to interference with cellular processes and high in vitro cytotoxicity. ${ }^{85}$ It must be commented that QDs are an extremely heterogeneous class of materials, varying in size, chemical composition, and surface characteristics and so the biocompatibility of QDs much depends on parameters like synthesis procedure or eventual surface modification. $^{85}$

The aggregation-induced emission (AIE) of organic fluorogens has shown to be a promising instrument for designing fluorescent markers for IVM approaches. In particular, AIE ultra-bright organic dots (AIE-dots) have been used as a labeling agent to image in vivo and in real-time skin, bone marrow, and brain vasculature. AIE-dots greatly surpass the fluorescence intensity provide by other compounds commonly used in IVM like Evans blue and commercially available QDs while showing low in vivo toxicity. ${ }^{86}$

Noble metal nanostructures, including gold nanoparticles and gold nanorods, have also been proposed in IVM approaches. However, their application for ischemia microscopy imaging is still limited despite the fact that this kind of nanomaterials finds analogous applications in MRI, PET, and CT. ${ }^{87,88}$

Natural-based nanomaterials have recently been proposed as an alternative to synthetic nanostructures as fluorescent probes for IVM, a fascinating example of which are the Tobacco mosaic virus-derived nanoparticles (TMV-NPs). TMV-NPs functionalized with the fluorophore BF3-NCS (boron trifluoride- $N$ chlorosuccinimide) have been used to image the brain vessels of living animals. Being a completely natural compound, TMVNPs are highly biocompatible and, more importantly, can be biodegraded and cleared from the body with ease. ${ }^{89}$ Recently, neutrophil membrane-derived nanovesicles loaded with resolvin D2 (RvD2) have been used as a drug delivery system to target specifically inflamed brain vasculature. ${ }^{90}$ One of the most exciting parts of this work was that the combination of Dil-stained particles with the blood vessels administration of bovine serum albumin marked with Cy 5.5 (BSA-Cy5), was able to provide realtime information of the live mouse brain circulation and to show the specific binding of the nanovesicles to the brain blood vessels..$^{90}$

Lastly, fluorescent gelatin nanoparticles (FGNPs) have been investigated as probes for IVM imaging of limb ischemia. FGNPs showed the ability to accumulate passively in ischemic sites and act as fluorescent markers to perform noninvasive in vivo fluorescent imaging. ${ }^{91}$ Due to their low toxicity and passive ischemia, targeting ability, these structures could be used as an imaging tool for the visualization of brain stroke. Even if IVM is less used when compared to the other techniques described in this work like MRI or CT, it is undeniable that it represents an unreplaceable tool to investigate in vivo biological processes at the cellular and even sub-cellular levels. In the future, the cross-talk between material science and microscopy will play a crucial point for the development of new imaging and labeling techniques able to be used both in research and even future clinical approaches. A summary of recent studies on IVM is presented in Table 5.

\section{Multimodal imaging}

To overcome the limitations that each of the above-mentioned methods present, new smart nano-diagnostic agents have been developed. These smart tailor-made systems can improve both diagnosis and prediction of stroke due to their ability to image the ischemic brain using more than one technique. This so-called multimodal imaging results in enhanced sensitivity and resolution capabilities that each one of the previously mentioned techniques cannot demonstrate by itself. In addition to multimodal imaging, a high number of these tailor-made nano-agents can also act as therapeutics providing a theranostic approach for cerebral ischemia and other diseases as well. A summary of these multimodal imaging/theranostic agents can be seen in Table 6 .

As a first example, MRI and photoacoustic imaging (PAI) were combined using multi-theranostic nano-beads made of mesoporous silica nanoparticles, embedding superparamagnetic iron oxide nanoparticles, and seeded with gold nanorods (GRMNBs). ${ }^{92}$

The goal of this study was the accurate guidance, through a static magnetic field, of umbilical cord mesenchymal stem cells (UMSCs) in the ischemic brain and the imaging of their therapeutic effect. It was shown that it is possible to increase the number of UMSCs to the ischemic tissue using magnetic guidance and to reduce the infarct size while simultaneously improving the functional recovery. Luciferase expressing UMSCs, embedding the GRMNBs, allowed the non-invasive bioluminescent monitoring of the homing of the UMSCs, demonstrating an increased number of UMSCs-GRMNBs in the peri-infarct regions when a static magnet was used.

Nanoparticles made of holmium, fluoride, and sodium, ${ }^{93,94}$ have also been used as multimodal nano-imaging agents. With a tunable size of few nanometers, PEGylated $\mathrm{NaHoF}_{4}$ or $\mathrm{BaHoF}_{4}$ nanoparticles were proven highly efficient as contrast agents both for X-ray computed tomography as well as ultra-high-field 


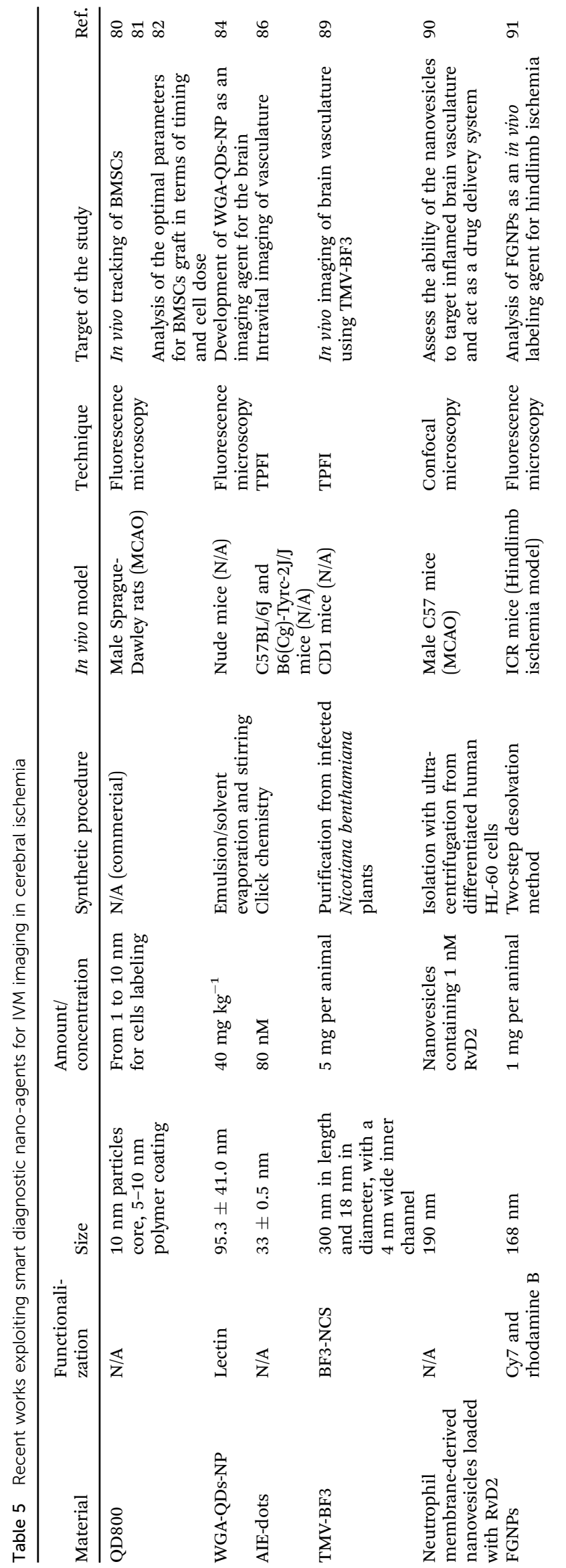

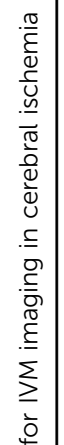

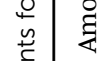

|

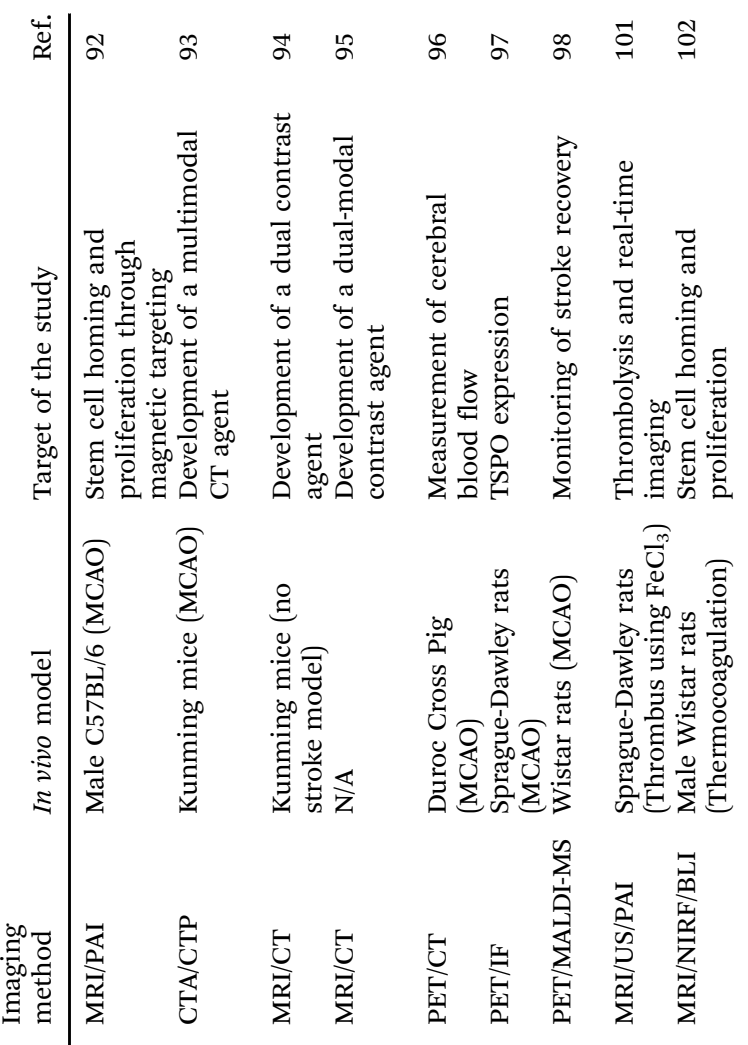

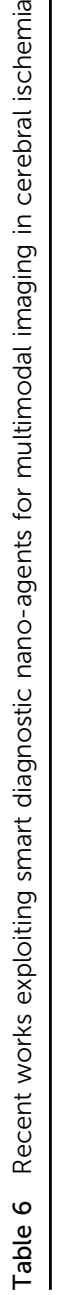


magnetic resonance imaging. Although both of these particles were designed as contrast agents, only the $\mathrm{BaHoF}_{4}$ have been studied in vivo for imaging stroke. In this work, ${ }^{93}$ multimodal computed tomography (CTA) and perfusion (CTP) were chosen as imaging techniques, and they demonstrated that these nanodiagnostics hold significant potential as contrast agents since they show increased contrast efficiency and reduced toxicity compared to the conventional iodine-based agents.

Another example of a dual-modal imaging agent developed for $\mathrm{CT}$ and MRI was fabricated by combining $\mathrm{CuO}$ and $\mathrm{Au}$ nanoparticles inside a polydopamine matrix. Even though this smart nano-diagnostic was not studied in a stroke model, the presented in vitro and ex vivo data demonstrated its potential use as an efficient contrast agent. ${ }^{95}$

A few more studies of dual imaging that are worth to be mentioned, despite non-based on nanomaterials, make use of PET imaging in combination with CT (measurement of cerebral blood flow), ${ }^{96}$ immunofluorescence (IF) (TSPO expression), ${ }^{97}$ and matrix-assisted laser desorption/ionization-mass spectroscopy (MALDI-MS) (monitoring of stroke recovery). ${ }^{98}$

SPECT is another technique that can also be combined with $\mathrm{CT}$ and provide useful information on the ischemic brain. To date, SPECT has already been used for several clinical applications, including trauma, dementia, and epilepsy. ${ }^{99}$ In SPECT imaging, a radiopharmaceutical is administrated to the patient, and then several images with a gamma-ray source are acquired at various positions, providing a $3 \mathrm{D}$ volume reconstruction of the region of interest. ${ }^{99}$ Recently, set-ups integrating SPECT and CT (commonly referred to as CT/SPECT) have found clinical application, although their use is still somewhat limited by the high cost of the technique itself. ${ }^{100}$

Last but not least, nano-diagnostic agents combining a triple modality have also been presented. Either using magnetic resonance (MR), ultrasounds (US), and $\mathrm{PAI}^{101}$ or $\mathrm{MR}$, near-infrared fluorescence (NIRF), and bioluminescence (BL) imaging, ${ }^{102}$ these tri-modal smart nano-diagnostics proved useful imaging tools for various diseases including ischemic stroke.

In the first case ${ }^{101}$ the combined imaging using MRI, US, and PAI was achieved using a tri-modal phase transition nanotheranostic agent based on SPIONs, perfluorohexane ( $\mathrm{PFH}$ ), and India ink. The inorganic nanoparticles, along with the organic $\mathrm{PFH}$ and the India ink, were encapsulated inside a peptide-modified poly(lactic-co-glycolic) acid matrix (EWVDVFe-Ink-PFH). The derived nano-agent resulted in the effective targeting of P-selectin in thrombi and their subsequent imaging as well as therapy (Fig. 6). It has to be noted that the therapeutic effect was based on the ability of the PFH to change its phase after a mild ultrasound, leading to thrombolysis. This work provided an example of a simple, effective, and non-invasive approach for the diagnosis and treatment of thrombosis, which can subsequently lead to embolic stroke.

In the latter case, where MR, NIRF, and BL were combined, ${ }^{102}$ commercial SPIONs labeled with a fluorescent dye (Molday $\mathrm{ION}^{\mathrm{TM}} 750$ ), were internalized by MSCs and provided real-time monitoring of homing and proliferation; this allowed the assessment of the cell graft condition in an in vivo model of stroke.

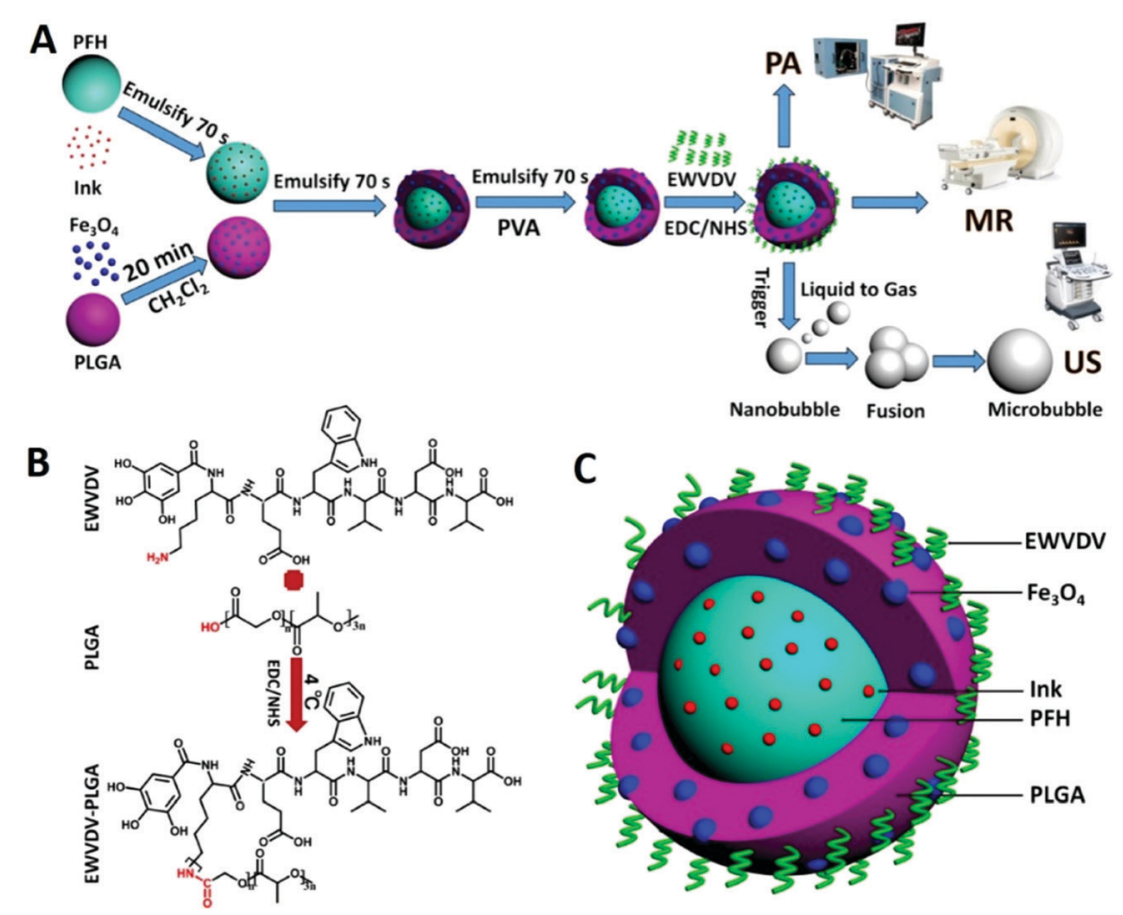

Fig. 6 Example of a smart theranostic nanosystem that can be used both for multimodal imaging as well as a therapeutic. (A) Schematic diagram of the fabrication procedure for the EWVDV-Fe-Ink-PFH nanoparticles and the imaging modalities. (B) The chemical formula of the peptide sequence EWVDV linked to the surface of the PLGA nanoparticles. (C) Schematic representation of the EWVDV-Fe-Ink-PFH nanoparticles. Adapted with permission from Xu et al. ${ }^{101}$ Copyright 2017 American Chemical Society. 


\section{Current limitations and future perspectives}

Despite the fact that the advances in the imaging of ischemic stroke have helped thousands of patients, there is still an immense need for better and faster imaging of the ischemic brain. Currently, the gold standards of stroke imaging rely on the use of CT and MRI.

Although both of these techniques provide fast imaging with a good spatiotemporal resolution and excellent tissue penetration depth, that can be used for an initial assessment of the patients' condition, they cannot always be used due to certain limitations (Table 7). CT is more widely accessible and at a lower cost than MRI, but in order to improve the low contrast imaging, the patients have to be administered with radioactive contrast agents, which in combination with the X-ray radiation arriving from the instrument, leads to increased radiation exposure that might be dangerous. In addition, CT is semiquantitative, and it does not always allow an accurate diagnosis of the real damage. On the other hand, MRI provides better spatial resolution with higher sensitivity and excellent tissue penetration, with almost no radiation (except the low nonionizing radiation of the generated electromagnetic fields) if compared to CT. Unfortunately, its high cost and the low contrast when it comes to brain ischemia act as limiting factors for its widespread use with respect to CT.
Two more techniques that can provide fast imaging with an excellent tissue penetration depth and also allow obtainment of quantitative data are PET and SPECT. Nevertheless, these techniques are even less common than MRI and CT, firstly due to the high cost and the limited availability in clinics and hospitals, and secondly due to increased exposure to radiation with respect to CT. Two more disadvantages of these techniques that excludes them as the first choice for imaging stroke lie in the low spatiotemporal resolution and in the difficulty in the quantification of the results.

One technique that is still under development and can overcome the limitations of the current imaging techniques is MPI. As previously mentioned, the excellent spatiotemporal resolution, the ability of quantification in the nano/pico-molar range, the lack of radiation, the no-limit in tissue penetration depth, and the very fast and $4 \mathrm{D}$ imaging render this technique as a promising successor for imaging brain ischemia. Finally, the last technique that could be potentially used for imaging stroke is IVM. Although IVM unmatched high resolution in the cellular and sub-cellular levels could provide information that no other technique can, the long list of weaknesses including invasiveness, time consumption, high cost, and reduced penetration does not allow its clinical use. Currently, to overcome some of the above-described limitations, a combination of imaging techniques like MRI/CT, PET/CT, PET/MRI/CT, PET/SPECT, PET/ MRI is used.

Table 7 Merits and demerits of the discussed imaging modalities above

\begin{tabular}{|c|c|c|c|}
\hline $\begin{array}{l}\text { Imaging } \\
\text { modality }\end{array}$ & Main features & Strength & Weakness \\
\hline CT & $\begin{array}{l}\text { Source: X-ray } \\
\text { Resolution: } 25-250 \mu \mathrm{m} \\
\text { Scan time: minutes-hours }\end{array}$ & $\begin{array}{l}\text { - Fast imaging } \\
\text { - Excellent tissue penetration depth } \\
\text { - Low cost } \\
\text { - Widely accessible } \\
\text { - High sensitivity }\end{array}$ & $\begin{array}{l}\text { - Low contrast } \\
\text { - Radiation exposure } \\
\text { - Use of contrast agents } \\
\text { (improved contrast) } \\
\text { - Semi-quantitative }\end{array}$ \\
\hline MRI & $\begin{array}{l}\text { Source: radio-waves } \\
\text { Resolution: } 25-100 \mu \mathrm{m} \\
\text { Scan time: minutes-hours }\end{array}$ & $\begin{array}{l}\text { - Low radiation } \\
\text { - No limit in tissue penetration } \\
\text { - Good spatial resolution } \\
\text { - High sensitivity }\end{array}$ & $\begin{array}{l}\text { - High cost } \\
\text { - Low contrast (for brain ischemia) }\end{array}$ \\
\hline PET & $\begin{array}{l}\text { Source: high energy } \gamma \text {-rays } \\
\text { Resolution: } 250 \mu \mathrm{m}-5 \mathrm{~mm} \\
\text { Scan time: } 1-5 \mathrm{~min}\end{array}$ & $\begin{array}{l}\text { - Excellent tissue penetration depth } \\
\text { - Quantitative measurements } \\
\text { - Fast imaging }\end{array}$ & $\begin{array}{l}\text { - High cost } \\
\text { - Radiation exposure } \\
\text { - Poor spatial and temporal resolution } \\
\text { - Limited availability }\end{array}$ \\
\hline SPECT & $\begin{array}{l}\text { Source: low energy } \gamma \text {-rays } \\
\text { Resolution: } 250 \mu \mathrm{m}-5 \mathrm{~mm} \\
\text { Scan time: } 1-5 \mathrm{~min}\end{array}$ & $\begin{array}{l}\text { - Excellent tissue penetration depth } \\
\text { - Quantitative measurements } \\
\text { - Fast imaging }\end{array}$ & $\begin{array}{l}\text { - Radiation exposure } \\
\text { - Difficult quantification } \\
\text { - Limited availability }\end{array}$ \\
\hline MPI & $\begin{array}{l}\text { Source: radio-waves } \\
\text { Resolution: }<1 \mathrm{~mm} \\
\text { Scan time: seconds-minutes }\end{array}$ & $\begin{array}{l}\text { - Low radiation } \\
\text { - No limit in tissue penetration } \\
\text { - Excellent spatiotemporal resolution (sensitivity) } \\
\text { - Quantification in the nano/pico-molar range } \\
\text { - Very fast and 4D imaging }\end{array}$ & $\begin{array}{l}\text { - Not commercially available } \\
\text { - New method; still under development }\end{array}$ \\
\hline IVM & $\begin{array}{l}\text { Source: visible, near infrared, } \\
\text { and infrared lasers } \\
\text { Resolution: } 1 \mu \mathrm{m}-1 \mathrm{~mm} \\
\text { Scan time: } 1-5 \mathrm{~min}\end{array}$ & - High resolution at a cellular/sub-cellular level & $\begin{array}{l}\text { - Poor penetration depth } \\
\text { - Invasive } \\
\text { - Time consuming } \\
\text { - High cost }\end{array}$ \\
\hline
\end{tabular}


It has to be stressed out that imaging of ischemic stroke is lucking, not only due to the inherent limitations of the used instruments, but also because of the used nano-agents. The administration of radioactive tracers not only enhances the radiation exposure, but also excludes specific individuals (pregnant and lactating women, for instance) from using CT, PET, and SPECT. Even if the encapsulation of these radiotracers in smart drug delivery systems reduces their toxicity during circulation in the blood, danger related to radiation still exist even after many years, rendering these agents the less suitable for patients. Excluding these techniques, the remaining ones, MRI and MPI, are depending on the use of magnetic nanoparticles or gadolinium-based agents (only for MRI). The use of gadolinium causes side-effects like nausea, headache, and dizziness, and can cause severe nephrogenic system fibrosis, especially to people with kidney problems. On the other hand, the use of iron oxide nanoparticles (IONPs) for imaging is considered the safest option compared to the previously described ones. Nevertheless, the up-to-date fabricated IONPs are not considered the 'solution to the problem' for several reasons. One of them lies in the fact that the IONPs cannot be administered without first being coated. The coating increases their colloidal stability as well as their circulation time, since it enhances their stealth properties rendering them able to avoid opsonization. Furthermore, a coating offers the ability to specifically target the brain resulting in a better biodistribution and in the ability to improve BBB penetration. Nevertheless, even if the reported coatings are improving specific properties of the used IONPs, their major disadvantage is the relatively high amount of particles that are needed in the ischemic area to provide fast and accurate results. To overcome these limitations, new IONPs with improved magnetic properties are every day presented in the literature. Nonetheless, up-to-date, there are no commercially available products that can significantly improve the spatial resolution of MRI and provide unambiguous data.

It is evident that in order to improve the outcome of patients with brain ischemia, fast and accurate imaging is a necessity. To achieve this, improvements both in the used instruments as well as in the used nano-agents need to occur. The development of MPI can counteract many limitations of the current imaging techniques, resolving in tandem, to some extent, the problem of the high concentration of IONPs to the brain. Smart nanoagents with enhanced circulation time and targeting ability can also improve the imaging capabilities of the current imaging techniques, while in parallel eliminating the potential side-effects. In the next couple of decades, we hope on the development of improved imaging techniques and instruments (e.g., MPI) that do not make use of ionizing energies or radiotracers but allow for a fast, accurate, and low-cost imaging of the ischemic brain.

\section{Conclusions}

Ischemic stroke is unarguably one of the biggest challenges in the biomedical field today. Despite the fact that several nanotechnological solutions have been presented in the past few years, still, they are far from achieving the complete therapy of the ischemic brain. The small therapeutic window, the existence of anatomical barriers, and the post-ischemia side-effects caused during reperfusion are also responsible for the inability of these treatments to lead to a complete recovery. In addition to these limitations, the current imaging techniques are not always sufficient to provide information that will undoubtedly identify patients with salvageable tissue or patients able to undergo therapy with tPA or mechanical thrombectomy. Smart nano-therapeutics able to deliver thrombolytic agents, while in parallel to ameliorate the neuronal damage caused by the subsequent neuro-inflammation and the overproduction of ROS and RNS, have already demonstrated encouraging results.

The combination of these smart nano-therapeutics with smart nano-diagnostics that are able to image the abnormalities of the ischemic tissue would increase the chances of a full recovery. Furthermore, multimodal imaging such as the combination of PET/CT/MRI and the development of new techniques like MPI hold great promise for better understanding of the pathophysiology and treatment of cerebral ischemia; this approach will also allow the monitoring of the real-time effect of the administered nanotherapeutics.

Although significant improvements have been achieved in the field of biomedical imaging, there is still space for improvement. For example, to further enhance the imaging of the diseased tissue, new nano-therapeutics with targeting specificity towards the ischemic brain and the ability to overcome the existing barriers need to be designed. Finally, it is evident that smart and multimodal nano-theranostics that can integrate multiple functionalities can improve the management and treatment of ischemic stroke, leading to the amelioration of post-stroke symptoms or even to the complete recovery of the stroke patients.

\section{Conflicts of interest}

There are no conflicts to declare.

\section{Acknowledgements}

This project has received funding from the European Union's Horizon 2020 research and innovation program under the Marie Sklodowska-Curie grant agreement No. 793644.

\section{References}

1 V. L. Feigin, A. A. Abajobir, K. H. Abate, F. Abd-Allah, A. M. Abdulle, S. F. Abera, G. Y. Abyu, M. B. Ahmed, A. N. Aichour and I. Aichour, et al., Lancet Neurol., 2017, 16, 877-897.

2 Types of stroke, https://www.cdc.gov/stroke/types_of_ stroke.htm, Accessed 21.01.2020.

3 M. Fisher, V. Vasilevko and D. H. Cribbs, Transl. Stroke Res., 2012, 3, 39-51.

4 C. Tapeinos, A. Larrañaga, F. Tomatis, J. Bizeau, A. Marino, M. Battaglini, A. Pandit and G. Ciofani, Adv. Funct. Mater., 2019, 30 . 
5 C. Brekenfeld, J. Gralla, C. Zubler and G. Schroth, Rofo, 2012, 184, 503-512.

6 W. S. Smith and A. J. Furlan, Stroke, 2016, 47, e23-26.

7 J. E. Fugate and A. A. Rabinstein, Neurohospitalist, 2015, 5, 110-121.

8 M. Mokin, S. A. Ansari, R. A. McTaggart, K. R. Bulsara, M. Goyal, M. Chen and J. F. Fraser, J. Neurointerv. Surg., 2019, 11, 215-220.

9 D. N. Granger and P. R. Kvietys, Redox Biol., 2015, 6, 524-551.

10 S. Kaviarasi, E. Yuba, A. Harada and U. M. Krishnan, J. Controlled Release, 2019, 300, 22-45.

11 C. S. Kidwell, J. A. Chalela, J. L. Saver, S. Starkman, M. D. Hill, A. M. Demchuk, J. A. Butman, N. Patronas, J. R. Alger and L. L. Latour, et al., JAMA, 2004, 292, 1823-1830.

12 D. Tang, W. Gao, Y. Yuan, L. Guo and X. Mei, Nanoscale Res. Lett., 2017, 12, 565.

13 H. Lusic and M. W. Grinstaff, Chem. Rev., 2013, 113, 1641-1666.

14 C. J. Ledezma and M. Wintermark, Radiol. Clin. North Am., 2009, 47, 109-116.

15 C. Leiva-Salinas and M. Wintermark, Neuroimaging Clin. North Am., 2010, 20, 455-468.

16 P. Vilela and H. A. Rowley, Eur. J. Radiol., 2017, 96, 162-172.

17 J. Vymazal, A. M. Rulseh, J. Keller and L. Janouskova, Insights Imaging, 2012, 3, 619-627.

18 D. V. Bonta and R. L. Wahl, Med. Phys., 2010, 37, 4897-4901.

19 J. Y. Kim, J. H. Ryu, D. Schellingerhout, I. C. Sun, S. K. Lee, S. Jeon, J. Kim, I. C. Kwon, M. Nahrendorf and C. H. Ahn, et al., Theranostics, 2015, 5, 1098-1114.

20 S. E. Seltzer, P. M. Shulkin, D. F. Adams, M. A. Davis, G. B. Hoey, R. M. Hopkins and M. E. Bosworth, AJR, Am. J. Roentgenol., 1984, 143, 575-579.

21 T. S. Desser, D. L. Rubin, H. Muller, G. L. McIntire, E. R. Bacon and J. L. Toner, Acad. Radiol., 1999, 6, 176-183.

22 Z. Starosolski, C. A. Villamizar, D. Rendon, M. J. Paldino, D. M. Milewicz, K. B. Ghaghada and A. V. Annapragada, Sci. Rep., 2015, 5, 10178.

23 S. You, H. Y. Jung, C. Lee, Y. H. Choe, J. Y. Heo, G. T. Gang, S. K. Byun, W. K. Kim, C. H. Lee and D. E. Kim, et al., J. Controlled Release, 2016, 226, 258-267.

24 P. Garrigue, L. Giacomino, C. Bucci, V. Muzio, M. A. Filannino, F. Sabatier, F. Dignat-George, P. Pisano and B. Guillet, Int. J. Stroke, 2016, 11, 117-126.

25 W. Zhang, Y. Shen, M. Liu, P. Gao, H. Pu, L. Fan, R. Jiang, Z. Liu, F. Shi and H. Lu, ACS Appl. Mater. Interfaces, 2017, 9, 39985-39993.

26 S. Rudkin, R. Cerejo, A. Tayal and M. F. Goldberg, Emerg. Radiol., 2018, 25, 659-672.

27 Y. Wang, G. Liu, D. Hong, F. Chen, X. Ji and G. Cao, Prog. Neurobiol., 2016, 141, 45-60.

28 M. G. Lansberg, G. W. Albers and C. A. Wijman, Cerebrovasc. Dis., 2007, 24, 1-10.

29 C. Vert, C. Parra-Farinas and A. Rovira, Eur. J. Radiol., 2017, 96, 125-132.

30 W. J. Powers, A. A. Rabinstein, T. Ackerson, O. M. Adeoye, N. C. Bambakidis, K. Becker, J. Biller, M. Brown,
B. M. Demaerschalk and B. Hoh, et al., Stroke, 2018, 49, e46-e110.

31 P. Ludewig, N. Gdaniec, J. Sedlacik, N. D. Forkert, P. Szwargulski, M. Graeser, G. Adam, M. G. Kaul, K. M. Krishnan and R. M. Ferguson, et al., ACS Nano, 2017, 11, 10480-10488.

32 M. R. Bashir, L. Bhatti, D. Marin and R. C. Nelson, J. Magn. Reson. Imaging, 2015, 41, 884-898.

33 D. Bobo, K. J. Robinson, J. Islam, K. J. Thurecht and S. R. Corrie, Pharm. Res., 2016, 33, 2373-2387.

34 T. Wang, Y. Hou, B. Bu, W. Wang, T. Ma, C. Liu, L. Lin, L. Ma, X. Lou and M. Gao, Small, 2018, 14, e1800573.

35 M. M. Mekawy, A. Saito, A. Sumiyoshi, J. J. Riera, H. Shimizu, R. Kawashima and T. Tominaga, Mater. Sci. Eng., C, 2019, 100, 485-492.

36 A. Saito, M. M. Mekawy, A. Sumiyoshi, J. J. Riera, H. Shimizu, R. Kawashima and T. Tominaga, J. Nanobiotechnol., 2016, 14, 19.

37 T. D. Farr, C. H. Lai, D. Grunstein, G. Orts-Gil, C. C. Wang, P. Boehm-Sturm, P. H. Seeberger and C. Harms, Nano Lett., 2014, 14, 2130-2134.

38 M. Gauberti, A. P. Fournier, F. Docagne, D. Vivien and S. Martinez de Lizarrondo, Theranostics, 2018, 8, 1195-1212.

39 W. N. Jin, X. Yang, Z. Li, M. Li, S. X. Shi, K. Wood, Q. Liu, Y. Fu, W. Han and Y. Xu, et al., J. Cereb. Blood Flow Metab., 2016, 36, 1464-1476.

40 X. Duan, L. Lu, Y. Wang, F. Zhang, J. Mao, M. Cao, B. Lin, X. Zhang, X. Shuai and J. Shen, Int. J. Nanomed., 2017, 12, 6705-6719.

41 L. Lu, Y. Wang, M. Cao, M. Chen, B. Lin, X. Duan, F. Zhang, J. Mao, X. Shuai and J. Shen, RSC Adv., 2017, 7, 15041-15052.

42 F. Zhang, X. Duan, L. Lu, X. Zhang, M. Chen, J. Mao, M. Cao and J. Shen, Cell Transplant., 2017, 26, 1648-1662.

43 C. Wang, G. Lin, Y. Luan, J. Ding, P. C. Li, Z. Zhao, C. Qian, G. Liu, S. Ju and G. J. Teng, Biomaterials, 2019, 197, 229-243.

44 H. Liu, A. Jablonska, Y. Li, S. Cao, D. Liu, H. Chen, P. C. Van Zijl, J. W. Bulte, M. Janowski and P. Walczak, et al., Theranostics, 2016, 6, 1588-1600.

45 C. Tang, C. Wang, Y. Zhang, L. Xue, Y. Li, C. Ju and C. Zhang, Nano Lett., 2019, 19, 4470-4477.

46 G. A. Deuchar, D. Brennan, W. M. Holmes, M. Shaw, I. M. Macrae and C. Santosh, Theranostics, 2018, 8, 1706-1722.

47 A. Moraga, V. Gomez-Vallejo, M. I. Cuartero, B. Szczupak, E. San Sebastian, I. Markuerkiaga, J. M. Pradillo, M. Higuchi, J. Llop and M. A. Moro, et al., J. Cereb. Blood Flow Metab., 2016, 36, 702-708.

48 M. Fujinaga, R. Luo, K. Kumata, Y. Zhang, A. Hatori, T. Yamasaki, L. Xie, W. Mori, Y. Kurihara and M. Ogawa, et al., J. Med. Chem., 2017, 60, 4047-4061.

49 T. Hosoya, D. Fukumoto, T. Kakiuchi, S. Nishiyama, S. Yamamoto, H. Ohba, H. Tsukada, T. Ueki, K. Sato and Y. Ouchi, J. Neuroinflammation, 2017, 14, 69.

50 A. T. Vesey, W. S. Jenkins, A. Irkle, A. Moss, G. Sng, R. O. Forsythe, T. Clark, G. Roberts, A. Fletcher and C. Lucatelli, et al., Circ. Cardiovasc. Imaging, 2017, 10. 
51 P. J. Kelly, P. Camps-Renom, N. Giannotti, J. Marti-Fabregas, S. Murphy, J. McNulty, M. Barry, P. Barry, D. Calvet and S. B. Coutts, et al., Stroke, 2019, 50, 1766-1773.

52 R. Sahathevan, T. Linden, V. L. Villemagne, L. Churilov, J. V. Ly, C. Rowe, G. Donnan and A. Brodtmann, Stroke, 2016, 47, 113-119.

53 K. L. Huang, J. L. Hsu, K. J. Lin, C. H. Chang, Y. M. Wu, T. Y. Chang, Y. J. Chang, C. H. Liu, M. Y. Ho and S. P. Wey, et al., EJNMMI Res., 2018, 8, 62.

54 R. Harada, N. Okamura, S. Furumoto, K. Furukawa, A. Ishiki, N. Tomita, T. Tago, K. Hiraoka, S. Watanuki and M. Shidahara, et al., J. Nucl. Med., 2016, 57, 208-214.

55 K. Lu, B. Zheng, J. J. Konkle, D. W. Hensley, P. Keselman, Z. W. Tay, R. D. Orendorff, E. Yu, X. Y. Zhou, B. Gunel, M. Bishop, L. Taylor, R. M. Ferguson, S. J. Kemp, A. P. Khandhar, K. M. Krishnan, S. M. Conolly and P. W. Goodwill, Design and Applications of Nanoparticles in Biomedical Imaging, Springer, 2017, ch. 6, pp. 69-94, DOI: 10.1007/978-3-319-42169-8.

56 M. Graeser, F. Thieben, P. Szwargulski, F. Werner, N. Gdaniec, M. Boberg, F. Griese, M. Moddel, P. Ludewig and D. van de Ven, et al., Nat. Commun., 2019, 10, 1936.

57 A. P. Khandhar, P. Keselman, S. J. Kemp, R. M. Ferguson, P. W. Goodwill, S. M. Conolly and K. M. Krishnan, Nanoscale, 2017, 9, 1299-1306.

58 R. Weigert, M. Sramkova, L. Parente, P. Amornphimoltham and A. Masedunskas, Histochem. Cell Biol., 2010, 133, 481-491.

59 S. Bok, T. Wang, C. J. Lee, S. U. Jeon, Y. E. Kim, J. Kim, B. J. Hong, C. J. Yoon, S. Kim and S. H. Lee, et al., Biomed. Opt. Express, 2015, 6, 3303-3312.

60 C. Heo, H. Park, Y. T. Kim, E. Baeg, Y. H. Kim, S. G. Kim and M. Suh, Sci. Rep., 2016, 6, 27818.

61 K. Svoboda and R. Yasuda, Neuron, 2006, 50, 823-839.

62 E. Beaurepaire, M. Oheim and J. Mertz, Opt. Commun., 2001, 188, 25-29.

63 M. J. Pittet and R. Weissleder, Cell, 2011, 147, 983-991.

64 A. Masedunskas, O. Milberg, N. Porat-Shliom, M. Sramkova, T. Wigand, P. Amornphimoltham and R. Weigert, Bioarchitecture, 2012, 2, 143-157.

65 B. Weigelin, G. J. Bakker and P. Friedl, J. Cell Sci., 2016, 129, 245-255.

66 S. Witte, A. Negrean, J. C. Lodder, C. P. de Kock, G. Testa Silva, H. D. Mansvelder and M. Louise Groot, Proc. Natl. Acad. Sci. U. S. A., 2011, 108, 5970-5975.

67 E. J. Yoder, Proc. SPIE-Int. Soc. Opt. Eng., 2002, 4620, 14-29.

68 S. Lee, B. M. Kang, J. H. Kim, J. Min, H. S. Kim, H. Ryu, H. Park, S. Bae, D. Oh and M. Choi, et al., Sci. Rep., 2018, 8, 13064.

69 J. Klohs, M. Grafe, K. Graf, J. Steinbrink, T. Dietrich, D. Stibenz, P. Bahmani, G. Kronenberg, C. Harms and M. Endres, et al., Stroke, 2008, 39, 2845-2852.

70 D. M. Hermann, C. Kleinschnitz and M. Gunzer, Ther. Adv. Neurol. Disord., 2018, 11, 1756286418798607.

71 Y. M. Morizawa, Y. Hirayama, N. Ohno, S. Shibata, E. Shigetomi, Y. Sui, J. Nabekura, K. Sato, F. Okajima and H. Takebayashi, et al., Nat. Commun., 2017, 8, 28.
72 M. Kislin, J. Sword, I. V. Fomitcheva, D. Croom, E. Pryazhnikov, E. Lihavainen, D. Toptunov, H. Rauvala, A. S. Ribeiro and L. Khiroug, et al., J. Neurosci., 2017, 37, 333-348.

73 T. B. Huff and J. X. Cheng, J. Microsc., 2007, 225, 175-182.

74 Y. Shi, D. Zhang, T. B. Huff, X. Wang, R. Shi, X. M. Xu and J. X. Cheng, J. Biomed. Opt., 2011, 16, 106012.

75 C. Andreou, S. A. Kishore and M. F. Kircher, J. Nucl. Med., 2015, 56, 1295-1299.

76 S. Yamazoe, M. Naya, M. Shiota, T. Morikawa, A. Kubo, T. Tani, T. Hishiki, T. Horiuchi, M. Suematsu and M. Kajimura, ACS Nano, 2014, 8, 5622-5632.

77 B. R. Smith, Z. Cheng, A. De, A. L. Koh, R. Sinclair and S. S. Gambhir, Nano Lett., 2008, 8, 2599-2606.

78 W. Cai, D. W. Shin, K. Chen, O. Gheysens, Q. Cao, S. X. Wang, S. S. Gambhir and X. Chen, Nano Lett., 2006, 6, 669-676.

79 X. Michalet, F. F. Pinaud, L. A. Bentolila, J. M. Tsay, S. Doose, J. J. Li, G. Sundaresan, A. M. Wu, S. S. Gambhir and S. Weiss, Science, 2005, 307, 538-544.

80 T. Sugiyama, S. Kuroda, T. Osanai, H. Shichinohe, Y. Kuge, M. Ito, M. Kawabori and Y. Iwasaki, Neurosurgery, 2011, 68, 1036-1047; discussion 1047.

81 M. Kawabori, S. Kuroda, T. Sugiyama, M. Ito, H. Shichinohe, K. Houkin, Y. Kuge and N. Tamaki, Neuropathology, 2012, 32, 217-226.

82 M. Kawabori, S. Kuroda, M. Ito, H. Shichinohe, K. Houkin, Y. Kuge and N. Tamaki, Neuropathology, 2013, 33, 140-148.

83 M. Ashrafizadeh, R. Mohammadinejad, S. K. Kailasa, Z. Ahmadi, E. G. Afshar and A. Pardakhty, Adv. Colloid Interface Sci., 2020, 278.

84 X. Gao, J. Chen, J. Chen, B. Wu, H. Chen and X. Jiang, Bioconjugate Chem., 2008, 19, 2189-2195.

85 R. Hardman, Environ. Health Perspect., 2006, 114, 165-172.

86 D. Ding, C. C. Goh, G. Feng, Z. Zhao, J. Liu, R. Liu, N. Tomczak, J. Geng, B. Z. Tang and L. G. Ng, et al., Adv. Mater., 2013, 25, 6083-6088.

87 H. Wang, T. B. Huff, D. A. Zweifel, W. He, P. S. Low, A. Wei and J. X. Cheng, Proc. Natl. Acad. Sci. U. S. A., 2005, 102, 15752-15756.

88 J. T. Del Bonis-O'Donnell, L. Chio, G. F. Dorlhiac, I. R. McFarlane and M. P. Landry, Nano Res., 2018, 11, 5144-5172.

89 A. Niehl, F. Appaix, S. Bosca, B. van der Sanden, J. F. Nicoud, F. Bolze and M. Heinlein, Front. Plant Sci., 2015, 6, 1244.

90 X. Dong, J. Gao, C. Y. Zhang, C. Hayworth, M. Frank and Z. Wang, ACS Nano, 2019, 13, 1272-1283.

91 J. Zhang, G. Wang, D. Mao, A. Han, N. Xiao, X. Qi, D. Ding and D. Kong, J. Nanomater., 2015, 2015, 1-7.

92 P. J. Chen, Y. D. Kang, C. H. Lin, S. Y. Chen, C. H. Hsieh, Y. Y. Chen, C. W. Chiang, W. Lee, C. Y. Hsu and L. D. Liao, et al., Adv. Mater., 2015, 27, 6488-6495.

93 J. Wang, D. Ni, W. Bu, Q. Zhou, W. Fan, Y. Wu, Y. Liu, L. Yin, Z. Cui and X. Zhang, et al., Biomaterials, 2015, 71, 110-118.

94 D. Ni, J. Zhang, W. Bu, C. Zhang, Z. Yao, H. Xing, J. Wang, F. Duan, Y. Liu and W. Fan, et al., Biomaterials, 2016, 76, 218-225. 
95 O. Perlman, A. Borodetsky, Y. Kauffmann, Y. Shamay, H. Azhari and I. S. Weitz, ACS Appl. Nano Mater., 2019, 2, 6124-6134.

96 E. A. Wright, C. D. d'Esterre, L. B. Morrison, N. Cockburn, M. Kovacs and T. Y. Lee, PLoS One, 2016, 11, e0158157.

97 M. Toth, P. Little, F. Arnberg, J. Haggkvist, J. Mulder, C. Halldin, B. Gulyas and S. Holmin, Brain Struct. Funct., 2016, 221, 1279-1290.

98 F. Henderson, P. J. Hart, J. M. Pradillo, M. Kassiou, L. Christie, K. J. Williams, H. Boutin and A. McMahon, Rapid Commun. Mass Spectrom., 2018, 32, 721-729.
99 J. M. Warwick, Metab. Brain Dis., 2004, 19, 113-123.

100 B. Bybel, R. C. Brunken, F. P. DiFilippo, D. R. Neumann, G. Wu and M. D. Cerqueira, Radiographics, 2008, 28, 1097-1113.

101 J. Xu, J. Zhou, Y. Zhong, Y. Zhang, J. Liu, Y. Chen, L. Deng, D. Sheng, Z. Wang and H. Ran, et al., ACS Appl. Mater. Interfaces, 2017, 9, 42525-42535.

102 H. R. da Silva, J. B. Mamani, M. P. Nucci, L. P. Nucci, A. T. Kondo, D. M. C. Fantacini, L. E. B. de Souza, V. Picanco-Castro, D. T. Covas and J. M. Kutner, et al., World J. Stem Cells, 2019, 11, 100-123. 